\title{
In Utero Exposure to Valproic Acid Induces Neocortical Dysgenesis via Dysregulation of Neural Progenitor Cell Proliferation/Differentiation
}

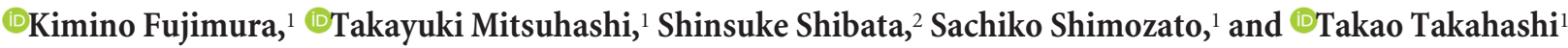 \\ 'Department of Pediatrics and ${ }^{2}$ Department of Physiology, Keio University School of Medicine, Shinjuku-ku, Tokyo 160-8582, Japan
}

\begin{abstract}
Valproic acid (VPA), a widely used antiepileptic drug, is an inhibitor of histone deacetylases, which epigenetically modify cell proliferation/differentiation in developing tissues. A series of recent clinical studies in humans reported that VPA exposure in utero impaired histogenesis and the development of the central nervous system, leading to increased risks of congenital malformation and the impairment of higher brain functions in children. In the present study conducted in mice, we report that VPA exposure in utero (1) increases the amount of acetylated histone proteins, (2) alters the expression of G1-phase regulatory proteins, (3) inhibits the cell cycle exit of neural progenitor cells during the early stage of neocortical histogenesis, and (4) increases the production of projection neurons distributed in the superficial neocortical layers in embryonic brains. Together, our findings show that VPA exposure in utero alters proliferation/ differentiation characteristics of neural progenitor cells and hence leads to the neocortical dysgenesis.
\end{abstract}

Key words: deacetylation; histone; neocortex; neural progenitor cell; neuronogenesis

\section{Significance Statement}

This study provides new insight into the mechanisms of how an altered in utero environment, such as drug exposure, affects the generation of neurons prenatally. The antiepileptic drug valproic acid (VPA) is a good target molecule as in utero exposure to VPA has been repeatedly reported to increase the risk of nervous system malformations and to impair higher brain functions in children. We show that VPA decreases the probability of differentiation of the neural progenitor cells (NPCs) in mice, resulting in an abnormally increased number of projection neurons in the superficial layers of the neocortex. Further, we suggest that histone deacetylase inhibition by VPA may be involved in the dysregulation of proliferation/differentiation characteristics of NPCs.

\section{Introduction}

Valproic acid (VPA) is a widely used antiepileptic drug, which when used during pregnancy has been reported to increase the risks of central nervous system anomalies (Jentink et al., 2010), of autism spectrum disorders (Bromley et al., 2013; Christensen et al., 2013), and of lowered intelligence quotient scores (Meador et

Received Jan. 19, 2016; revised Sept. 2, 2016; accepted Sept. 12, 2016.

Author contributions: K.F., T.M., and T.T. designed research; K.F., T.M., and S. Shibata performed research; K.F., T.M., and S. Shimozato analyzed data; K.F., T.M., S. Shibata, and T.T. wrote the paper.

This work was supported by Grants-in-Aid for Scientific Research (B: 20390299, 23390276, and 26293248 for T.T.; C: 25461560 for T.M.) and a Grant-in-Aid for Young Scientists (B: 22791001 for T.M. and 22791038 for S. Shimozato) of the Japan Society for the Promotion of Science, and by the Mother and Child Health Foundation, the Japan Epilepsy Research Foundation, Keio Gijuku Fukuzawa Memorial Fund for the Advancement of Education and Research, Kawano Masanori Memorial Public Interest Incorporated Foundation for Promotion of Pediatrics, and the Japan Foundation for Pediatric Research Grant (for T.M.). We thank Dr. Takayuki Abe for suggestions regarding statistical analyses, Dr. Satoshi Narumi, and Ms. Namiko Saito for supporting manuscript preparation.

The authors declare no competing financial interests.

Correspondence should be addressed to Takao Takahashi, MD, PhD, Department of Pediatrics, Keio University School of Medicine, 35 Shinanomachi, Shinjuku-ku, Tokyo, 160-8582, Japan. E-mail: ttakahashi@keio.jp DOI:10.1523/JNEUROSCI.0229-16.2016

Copyright $\odot 2016$ the authors $\quad 0270-6474 / 16 / 3610908-12 \$ 15.00 / 0$ al., 2013) in postnatal children. Thus, the International League Against Epilepsy recommends avoiding the administration of VPA to women of childbearing age (Tomson et al., 2015).

In addition to its antiepileptic activity, VPA inhibits histone deacetylases (HDACs; Göttlicher et al., 2001; Phiel et al., 2001). HDACs compress chromatin structures through the deacetylation of lysine residues in the $\mathrm{N}$ termini of core histone proteins, thereby decreasing the transcriptive activities of genes (Strahl and Allis, 2000; Wade, 2001). Especially in developing mammalian tissues, VPA exposure has been reported to alter the expression patterns of cell cycle-related genes in an epigenetic manner and to dysregulate the cell proliferation/differentiation characteristics of stem/progenitor cells (Tou et al., 2004).

We hypothesized that VPA exposure in utero may induce neocortical dysgenesis by altering the cell cycle kinetics of neural progenitor cells (NPCs) via its inhibitory activity on HDACs. In this study, we analyzed the proliferation/differentiation characteristics of NPCs under VPA exposure in utero, and conducted a quantitative analysis of the neocortical archi- 
tecture in postnatal mice based on a mathematical model of neocortical histogenesis (Takahashi et al., 1995a, 1996b).

\section{Materials and Methods}

Animal maintenance and VPA administration. Pregnant CD1 mice (Sankyo Labo Service) were maintained under a $12 \mathrm{~h}$ light/dark schedule. Since the half-life of VPA is reported to be $<1 \mathrm{~h}$ in mice (Nau, 1985), we administered $0.4 \%$ VPA (Sigma-Aldrich) or distilled water as a control in drinking water from embryonic day 1 (E1) until birth. We limited the number of pups reared by a single mother to eight to standardize the nutritive conditions of the pups born to these prolific CD-1 dams. Embryos and postnatal mice of either sex were used. All the experimental procedures were in full compliance with the institutional guidelines of the Laboratory Animal Center, Keio University School of Medicine.

Tissue processing for histological analysis. Postnatal mice were perfused transcardially with $4 \%$ paraformaldehyde (Sigma-Aldrich), unless specified. The analysis was conducted using serial coronal sections with $4 \mu \mathrm{m}$ thickness, which included the dorsomedial primary somatosensory area of neocortices (field 1; Caviness, 1975).

As for the analysis in embryos, whole heads were immersion fixed with $4 \%$ paraformaldehyde overnight at $4^{\circ} \mathrm{C}$. Serial coronal sections of forebrains/telencephala were cut at a $4 \mu \mathrm{m}$ thickness, including the dorsomedial regions of the cerebral walls that correspond to the future field 1 (Takahashi et al., 1995a).

Measurement of the surface length of the telencephala. The neocortical sections of postnatal day $4(\mathrm{P} 4)$ and $\mathrm{P} 21$ mice were stained with $0.1 \%$ cresyl violet (Sigma-Aldrich), and were photographed by a digital camera (D700, Nikon) attached to an upright fluorescence microscope (BX51, Olympus). The surface length from the longitudinal cerebral fissure to the rhinal fissure was measured by ImageJ 1.47 software (National Institutes of Health) as an index of the surface area, which approximately represents the tangential growth of the neocortices. Eight or more brains from $\geq 4$ litters were analyzed for the VPA-exposed mice and controls. For each brain, four nonconsecutive sections were measured.

Measurement of the number of neurons in the neocortices. The numbers of (1) GABAergic neurons, (2) non-GABAergic neurons, and (3) glial cells in the neocortices of P21 mice were analyzed, as previously described (Goto et al., 2004; Mitsuhashi et al., 2010). Briefly, the P21 mice were perfused transcardially with $4 \%$ paraformaldehyde and $0.5 \%$ glutaralaldehyde (Kanto Chemical) in $0.1 \mathrm{M}$ PBS. The sections were immunohistochemically stained using anti-GABA antibody (1:1000; A2052, Sigma-Aldrich, RRID: AB_477652; $4^{\circ} \mathrm{C}$, overnight) as a primary antibody, Alexa Fluor 555 anti-rabbit IgG antibody (1:600; A-31572, Thermo Fischer Scientific, RRID: AB_10562716; room temperature, $1.5 \mathrm{~h}$ ) as a secondary antibody, and bisbenzimide trihydrochloride (1:300 of $1 \%$ solution; H33342, Sigma-Aldrich; room temperature, $1.5 \mathrm{~h}$ ) as a counterstaining reagent. The immunologically stained slides were photographed by digital camera, and images of the sections were examined by Zen lite 2011 software (Carl Zeiss Microscopy). Six or more brains from $\geq 3$ litters were analyzed for the VPA-exposed mice and controls. For each brain, four nonconsecutive sections were analyzed. Additionally, GABA/GAD67 double staining and Cux1/CTIP2 double staining were conducted using anti-GAD67 antibody (1:250; MAB5406, Millipore Bioscience Research Reagents, RRID: AB_2278725; $4^{\circ} \mathrm{C}$, overnight), antiCux1 antibody (1:50; sc-13024, Santa Cruz Biotechnology, RRID: AB_2261231; $4^{\circ} \mathrm{C}$, overnight), anti-CTIP2 antibody (1:250; ab18465, Abcam, RRID: AB_2064130; $4^{\circ} \mathrm{C}$, overnight), and the aforementioned anti-GABA antibody as primary antibodies, and Alexa Fluor 488 antimouse IgG antibody (1:600; A-11029, Thermo Fischer Scientific, RRID: AB_2534088; room temperature, $1.5 \mathrm{~h}$ ) and Alexa Fluor 488 anti-rat IgG antibody (1:600; A-11006, Thermo Fischer Scientific, RRID: AB_ 2534074; room temperature, $1.5 \mathrm{~h}$ ) in addition to the aforementioned secondary antibody in the sections of P21 neocortices fixed with $4 \%$ paraformaldehyde.

As for the analysis on P4 rats, we counted the number of neurons in sections stained only with $0.1 \%$ cresyl violet. This was because the expression level of GABA on P4 rats had been reported to be $\sim 50 \%$ compared with that in adult rats, and the sensitivity of immunohistochemical staining against GABA was considered to be insufficient for the analysis

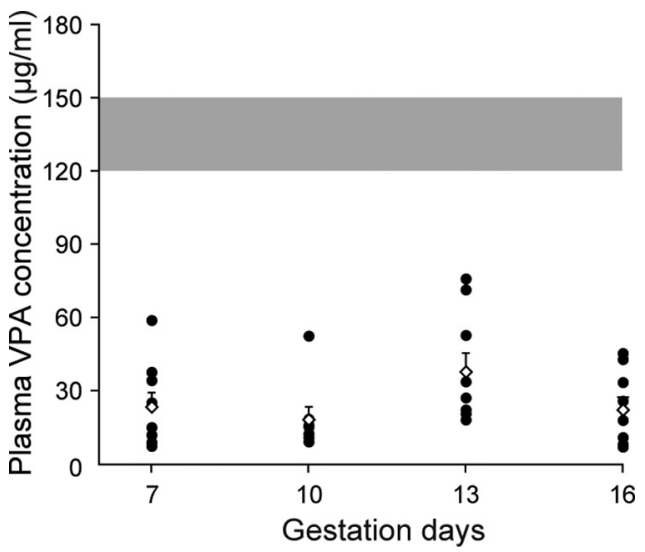

Figure 1. The plasma concentration of valproic acid (VPA) of pregnant mothers under ad libitum access to drinking water containing $0.4 \% \mathrm{VPA}$, measured on gestation day $7,10,13$, and 16. Closed circle, Plasma VPA concentration of each mouse; open squares, mean. The gray box indicates the plasma VPA concentration reportedly increased seizure threshold by $50 \%$ in mice (Löscher, 1999). Error bars, SEM.

(Coyle and Enna, 1976). Eight brains from $\geq 4$ litters were analyzed for the VPA-exposed mice and controls. For each brain, four nonconsecutive sections were analyzed.

Golgi staining. Brains of P21 mice were removed and were immersed in an impregnation solution using a commercially available kit (FD Rapid GolgiStain kit, FD Neurotechnologies) based on the Golgi's silver staining technique. The brains were cut into coronal sections of $200 \mu \mathrm{m}$ thickness and were stained according to the manufacturer's protocol. Images were captured by a microscope (BZ-9000, Keyence). Eight brains from four litters were analyzed for the VPA-exposed mice and controls.

Measurement of the size of embryos and forebrains/telencephala and of the thickness of cerebral walls. E11 embryos were photographed using a digital camera attached to a dissecting microscope (SZX9, Olympus). The crown-rump length and the maximum rostrocaudal length of the forebrains were measured by ImageJ 1.47 software. Fifteen embryos from five litters were measured for the VPA-exposed embryos and controls.

Coronal sections, including the mediolateral cerebral walls of E10, E11, E12, E14, E16, E17, and E18 brains, were stained with $0.1 \%$ basic fuchsin (Sigma-Aldrich), and were photographed with a slide scanner (Nano Zoomer-XR, Hamamatsu Photonics). The maximum mediolateral length (width) of the forebrains/telencephala and the thickness of the cerebral walls were measured by NDP.view2 software (Hamamatsu Photonics). Eight or more forebrains/telencephala from $\geq 5$ litters were measured for the VPA-exposed embryos and controls on each embryonic day. Four nonconsecutive sections were measured for each forebrain/ telencephalon.

Estimation of the cell cycle length of NPCs in the ventricular zone. $\mathrm{Cu}-$ mulative 5-bromo-2' deoxyuridine (BrdU) labeling analysis was conducted for the estimation of the cell cycle length of NPCs in the ventricular zone (VZ) on E10, E11, E12, E14, and E16, as previously described (Takahashi et al., 1995a). After exposure to BrdU (SigmaAldrich), coronal sections of the dorsomedial cerebral walls were immunohistochemically stained using anti-BrdU antibody (1:50; MCA2060, AbD Serotec, RRID: AB_323427; $4^{\circ} \mathrm{C}$, overnight) as a primary antibody, and Alexa Fluor 555 anti-rat IgG antibody (1:600; A-21434, Thermo Fischer Scientific, RRID: AB_2535855; room temperature, $1.5 \mathrm{~h}$ ) as a secondary antibody. Images of the sections were captured by a laser confocal microscope (LSM 700, Carl Zeiss Microscopy) and were examined by ZEN lite 2011 software. BrdU labeling indices (LIs; ratios of BrdU-positive nuclei to total number of nuclei) were calculated within the cerebral wall (Takahashi et al., 1995a). The LIs of the VZ were plotted against the experimental interval, and regression lines were calculated. The maximum LI corresponded to the growth fraction of the VZ. We calculated the total cell cycle length $\left(T_{C}\right)$ and the length of the S-phase $\left(T_{S}\right)$ from the regression lines of the LIs. $T_{C}-T_{S}$ corresponds to the period required for the $\mathrm{LI}$ to reach its maximum. $T_{C} / T_{S}$ corresponds to 
the $y$-intercept of the regression line. The combined length of the G2 phase and the M phase $\left(T_{C^{2}}+M_{M}\right)$ corresponds to the time required to label all mitotic cells at the ventricular surface. The length of $\mathrm{G} 1$ phase $\left(T_{G 1}\right)$ was calculated as $T_{C}-\left(T_{S}+T_{G 2}+M\right)$. A total of $\geq 20$ forebrains/telencephalons from $\geq 10$ litters were analyzed for the VPA-exposed embryos and controls on each embryonic day. Four nonconsecutive sections were measured for each forebrain/telencephalon.

Identification of the end of neuronogenetic period in the VZ. To identify the end of the neuronogenetic period, the disappearance of the VZ was confirmed by (1) the disappearance of the S-phase zone and (2) the attenuation of immunostaining for Pax6, a marker for progenitors in the VZ. Coronal sections of dorsomedial cerebral walls were prepared $2 \mathrm{~h}$ after BrdU injection on E17 and E18, and then immunohistochemically double-stained for Pax6/BrdU using an anti-Pax6 antibody (1: 500; PD022, Medical and Biological Laboratories, RRID: $\mathrm{AB} \_1520876 ; 4^{\circ} \mathrm{C}$, overnight) and Alexa Fluor $64 \overline{7}$ anti-rabbit IgG antibody (1: 600; A-21245, Thermo Fischer Scientific, RRID: AB_2535813; room temperature, $1.5 \mathrm{~h}$ ) in addition to the aforementioned anti-BrdU antibody. Three brains from three litters were analyzed for the VPA-exposed embryos and controls on each embryonic day.

Analysis of the probability of cell cycle exit. Analysis of the probability of cell cycle exit (quiescent or $\mathrm{Q}$ fraction) was conducted on E10, E11, E12, E14, and E16 as previously described (Takahashi et al., 1996b; Tarui et al., 2005; Mitsuhashi et al., 2010). To define a $2 \mathrm{~h}$ cohort of NPCs that exit the S phase, 5-iodo-2' deoxyuridine (IdU; Sigma-Aldrich) and BrdU were administered to pregnant mice by intraperitoneal injections at 7:00 A.M. and 9:00 A.M., respectively. This time difference was chosen because BrdU is not incorporated into NPCs beyond $3.5 \mathrm{~h}$ following a single injection (Takahashi et al., 1992), leading to a decline in the BrdU LIs. Then, the mice were divided into two groups: (1) one in which BrdU injection was administered every $3 \mathrm{~h}$ ( $\mathrm{Q}$ experiment), and (2) a second group in which BrdU was not administered again ( $\mathrm{P}+\mathrm{Q}$ experiment; $\mathrm{P}$ : proportion of daughter cells that remain proliferative, $\mathrm{P}=1-\mathrm{Q}$ ). In both groups, mice were sacrificed after more than $T_{C}-T_{S}$ hour had passed after the initial BrdU injection. Coronal sections of the dorsomedial cerebral walls were immunohistochemically double stained using anti-IdU/BrdU antibody ( $1: 25 ; 347580$, Becton Dickinson, RRID: AB_400326; $4^{\circ} \mathrm{C}$, overnight $)$ in addition to the aforementioned anti-BrdU antibody. A total of $\geq 8$ forebrains/telencephala from $\geq 3$ litters were analyzed each for the VPA-exposed embryos and controls on each embryonic day. For each forebrain/telencephalon, 4-6 nonconsecutive sections were measured.

Measurement of Pax6-positive and/or Tbr2-positive nuclei. Coronal sections of E16 dorsomedial cerebral walls were immunohistochemically double stained for Pax6 and Tbr2 using an anti-Pax6 antibody (1:100; AB528427, Developmental Studies Hybridoma Bank, RRID: $\mathrm{AB} \_528427 ; 4^{\circ} \mathrm{C}$, overnight $)$ and an anti-Tbr2 antibody (1:200; ab23345, Abcam, RRID: AB_778267; $4^{\circ} \mathrm{C}$, overnight). Images of the sections were captured by the laser confocal microscope and the numbers of Pax6positive and/or Tbr2-positive nuclei were counted with ZEN lite 2011
C
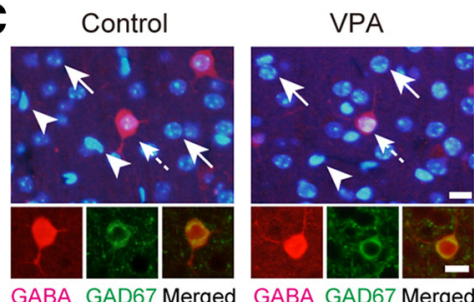

D

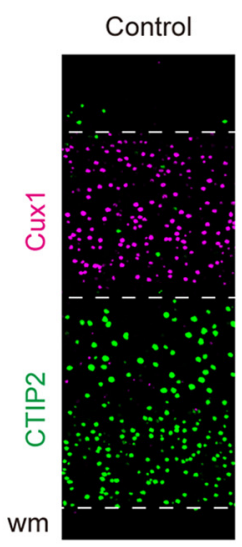

VPA

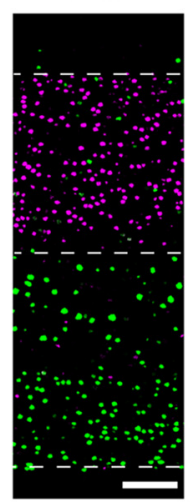

$\mathbf{F}$

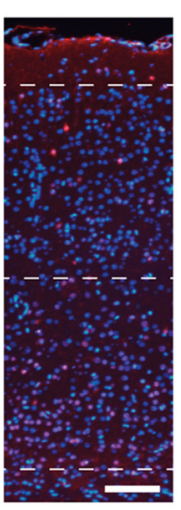

VPA

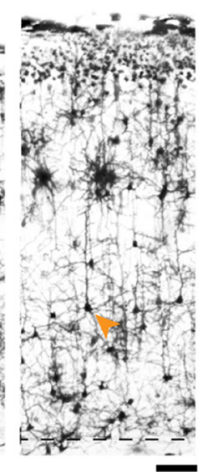

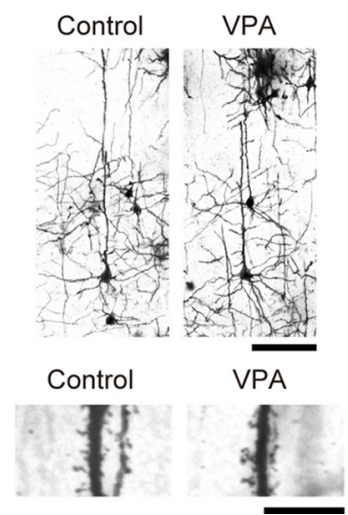

Figure 2. Effects of VPA exposure in utero on the histological architecture of the neocortices on postnatal day 21 (P21). $A, A$ low-magnification view of a coronal section of a VPA-exposed brain stained with cresyl violet. Black squares correspond to the primary somatosensory area of neocortices (field 1). Scale bar, $1 \mathrm{~mm}$. $\boldsymbol{B}$, High-power views of the neocortical field 1 in controls and I/II-IV, II-IV/V-VI, and gray matter/white matter (wm). Scale bar, $100 \mu \mathrm{m}$. C, A higher magnification of field 1, immunohistochemically double stained for GABA and GAD67. Dashed arrow, GAD67-positive GABAergic interneurons; arrows, non-GABAergic Cux1-positive neurons; green, CTIP2-positive neurons. Scale bar, $100 \mu \mathrm{m}$. E, Field 1 stained with Golgi's silver staining technique. Orange arrowheads, Pyramidal neurons. Scale bar, $100 \mu \mathrm{m}$. Note that brains stained with Golgi's silver staining technique are larger than brains shown in $\boldsymbol{A}-\boldsymbol{D}$ due to the difference in fixing condition. $\boldsymbol{F}$, Pyramidal neurons indicated by the orange arrowheads in $\boldsymbol{E}$. Scale bar, $100 \mu \mathrm{m}$. $\boldsymbol{G}$, Apical dendrites of the pyramidal neurons shown in $\boldsymbol{F}$. Scale bar, $10 \mu \mathrm{m}$.

software using its range indicator. Tbr2 expression was considered positive when its fluorescence level was clearly above background level; Pax6 expression was considered positive when its fluorescence level was clearly above background level and was detectable over $50 \%$ of the nucleus (Englund et al., 2005; Kowalczyk et al., 2009). Six telencephala from three litters were analyzed for the VPA-exposed embryos and controls. For each telencephalon, four nonconsecutive sections were evaluated.

Number and laminar fate of the Q cells in the postnatal neocortices. IdU and $\mathrm{BrdU}$ were administered to the pregnant mice in the same manner as in the Q experiment on E16, and the coronal sections of the field 1 of neocortices on P21 were cut (Takahashi et al., 1999). In addition to the antibodies used in the $\mathrm{Q}$ fraction analysis, anti-calbindin antibody (1:500; AB1778, Millipore Bioscience Research Reagents, RRID: AB_2068336; $4^{\circ} \mathrm{C}$, overnight) was applied to serve as a marker of layer II 
in the neocortices. The number of IdU-positive/BrdU-negative neurons, i.e., the "E16-born" Q cells, was counted. Four brains from three litters were examined for the VPA-exposed mice and controls. For each brain, four nonconsecutive sections were analyzed. Additionally, the E16-born Q cells were costained for Cuxl using the aforementioned anti-Cux1 antibody, to assess the association between the E16-born Q cells and the Cux1-positive superficial layer neurons.

Estimation of the cell cycle length and the population volume of secondary proliferative population. Percent labeled mitosis method was conducted to estimate the $T_{C}$ of the secondary proliferative population (SPP) on E16, as previously described (Takahashi et al., 1995b; Miyama et al., 1997). A total of $\geq 29$ telencephala from 12 litters were analyzed for the VPA-exposed embryos and controls. For each telencephalon, four nonconsecutive sections were analyzed.

Based on the fact that the SPP does not undergo interkinetic nuclear movement, separation of the VZ and the SPP population was conducted by the $1 \mathrm{~h}$ cohort method as previously described, provided that IdU/ BrdU double-staining method was used for detection of the $1 \mathrm{~h}$ cohort cells (Takahashi et al., 1995b; Miyama et al., 1997). Additionally, the aforementioned anti-Tbr2 antibody was used to assess the association between the SPP cells and the Tbr2-positive basal progenitors (BPs; Englund et al., 2005). The number of proliferative cells in the VZ and the SPP was calculated by multiplication of the number of $1 \mathrm{~h}$ cohort cells by their estimated $T_{C}$ s. Nine or more telencephala from $\geq 4$ litters were analyzed for the VPA-exposed embryos and controls. For each telencephalon, 4-6 nonconsecutive sections were analyzed.

Furthermore, the number of BrdU-positive nuclei was counted in the sections that were prepared $2 \mathrm{~h}$ after BrdU injection on E18. Eight telencephala from $\geq 3$ litters were analyzed for the VPA-exposed embryos and controls. For each telencephalon, four nonconsecutive sections were analyzed.

Terminal deoxynucleotidyl transferase-mediated dUTP nick-end labeling staining. Postnatal mice were perfused with $10 \%$ neutral buffered formalin (Nacalai Tesque) on P4. Terminal deoxynucleotidyl transferase-mediated dUTP nick-end labeling (TUNEL)-positive nuclei were detected by a commercially available kit (ApopTag Plus Peroxydase In Situ Apoptosis detection kit, Millipore Bioscience Research Reagents). Fifteen brains from five litters were analyzed for the VPA-exposed mice and controls. For each brain, four nonconsecutive sections were analyzed.

Immunoblot analysis. The cerebral walls of E12 embryos were homogenized manually in 10 volumes of an ice-cold low-osmolality lysis buffer (0.5 м HEPES-KOH, pH 7.8, $1 \mathrm{~m} \mathrm{KCl,} 0.5$ м EDTA, 1 mм DTT, proteinase inhibitor mixture) for separation of nuclear fraction, followed by application of a high osmolality lysis buffer (0.5 M HEPES-KOH, pH 7.8, $1 \mathrm{~m}$ $\mathrm{KCl}, 1 \mathrm{M} \mathrm{MgCl}, 68 \%$ glycerol, $1 \mathrm{~mm}$ DTT, proteinase inhibitor mixture). After fragmentation of genomic DNA by sonication, SDS-polyacylamidegel electrophoresis was performed using $10 \mu \mathrm{g}$ of the nuclear protein. Precision Plus Protein WesternC standards (\#161-0376, BioRad Laboratories) were applied to the gels as molecular weight markers. The following antibodies were used for immunoblot analysis: anticyclinD1 antibody (1:250; RM-9104, Thermo Fischer Scientific, RRID: AB_720758; $4^{\circ} \mathrm{C}$, overnight), anti-cyclin-dependent kinase (cdk) 2 antibody (1:250; sc-163, Santa Cruz Biotechnology, RRID: AB_631215; $4^{\circ} \mathrm{C}$, overnight), anti-cdk4 antibody (1:250; sc-260, Santa Cruz Biotechnology, RRID: AB_631219; $4^{\circ} \mathrm{C}$, overnight), and anti-p2 $7^{\text {Kip } 1}$ antibody (1: 500; 610241, Becton Dickinson, RRID: AB_397636; $4^{\circ} \mathrm{C}$, overnight). Signal intensities were standardized by comparison with those of $\beta$-actin protein. For each test, the cerebral walls of 12-15 embryos were collected from a single mother for each of the VPA-exposed embryos and controls. Three independent tests were conducted for analysis of each protein.

Measurement of the amount of total acetylated histone H3 protein. The cerebral walls of E12 embryos were homogenized in cold PBS, and the number of cells was counted for standardization. The cells were homogenized in 10 volumes of acid lysis buffer (10 mM HEPES-KOH, pH 7.8, $1.5 \mathrm{~mm} \mathrm{MgCl} 2,10 \mathrm{~mm} \mathrm{KCl}, 0.5 \mathrm{~mm}$ DTT, $0.2 \mathrm{M} \mathrm{HCl}$, proteinase inhibitor mixture) for extraction of histone proteins, followed by application of ice-cold acetone (Sigma-Aldrich) for protein purification. The amount of total acetylated histone $\mathrm{H} 3$ protein was measured by a commercially available kit based on an enzyme-linked immunosorbent assay (EpiQuik total
A

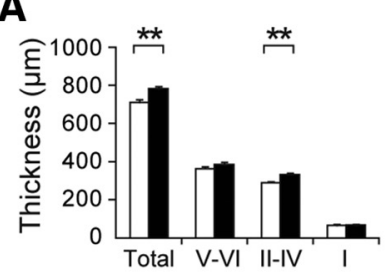

B

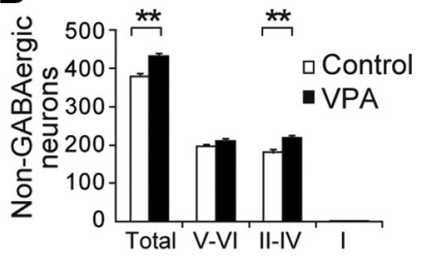

C

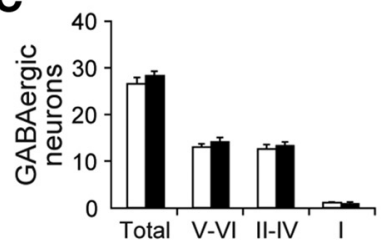

D

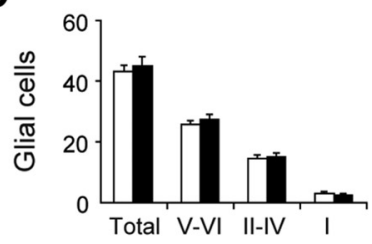

E
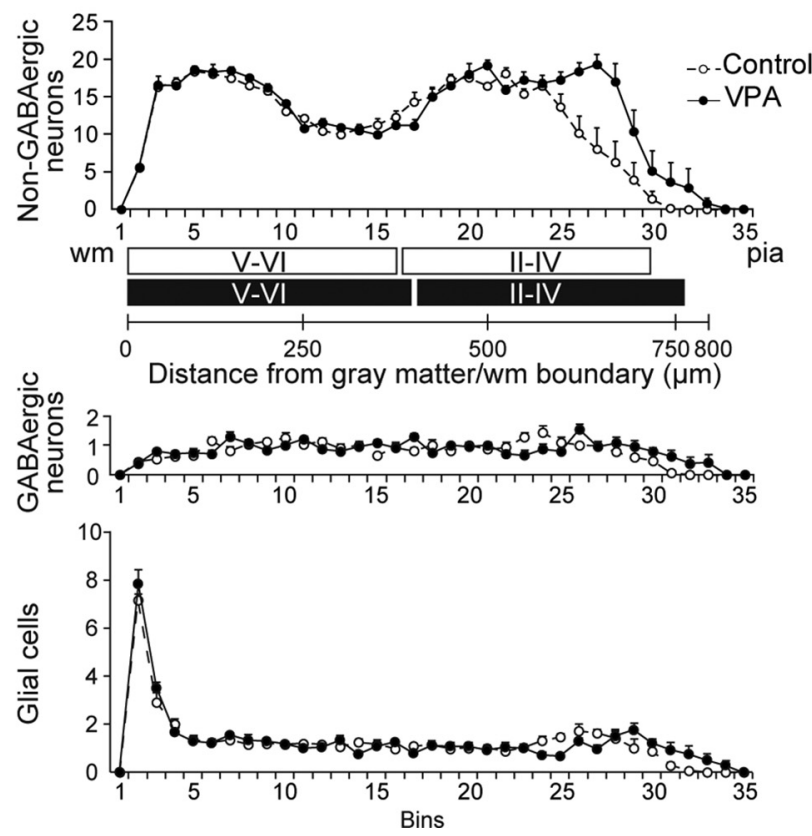

Figure 3. Effects of VPA exposure in utero on the neocortical thickness and the numbers of neurons and glial cells on P21. $\boldsymbol{A}$, The thickness of representative neocortical layers. $\boldsymbol{B}$, The number of non-GABAergic projection neurons in representative neocortical layers. Counting areas, $250 \mu \mathrm{m}$ in width and the total neocortical thickness in height. $C$, The number of GABAergic interneurons. $\boldsymbol{D}$, The number of glial cells. $\boldsymbol{E}$, The number of non-GABAergic projection neurons, GABAergic interneurons, and glial cells counted in each bin ( $250 \mu \mathrm{m}$ in width and $25 \mu \mathrm{m}$ in height) lined serially from the gray matter/white matter boundary (wm) to the pial surface (pia) in the neocortical field 1. Analysis using a linear mixed-effects model showed a significant interaction between the increased number of nonGABAergic projection neurons and layers II-IV in the VPA-exposed mice $(p=0.004)$. White and black boxes under the abscissa indicate layers V-VI/II-IV in the neocortices of controls and the VPA-exposed mice, respectively. ${ }^{* *} p<0.01$. Error bars, SEM.

histone $\mathrm{H} 3$ acetylation detection fast kit, Epigentek). For each test, the cerebral walls of 12-15 embryos were collected from a single control and VPAexposed mother. Four independent measurements were conducted.

Statistical analysis. Statistical significance was evaluated by two-sided Student's $t$ tests in which $p$ values of $<0.05$ were regarded as statistically significant. Additionally, analysis using a linear mixed-effects model was conducted when indicated.

\section{Results}

VPA exposure in utero increased the thickness of superficial neocortical layers on P21

The plasma concentration of VPA in the dams was $23.5 \pm 5.7$ $\mu \mathrm{g} / \mathrm{ml}$ on gestation day 7 (mean $\pm \mathrm{SEM}, n=9$ ), $18.3 \pm 5.0 \mu \mathrm{g} / \mathrm{ml}$ 
A

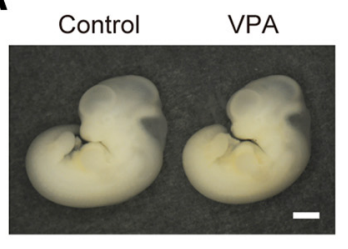

D

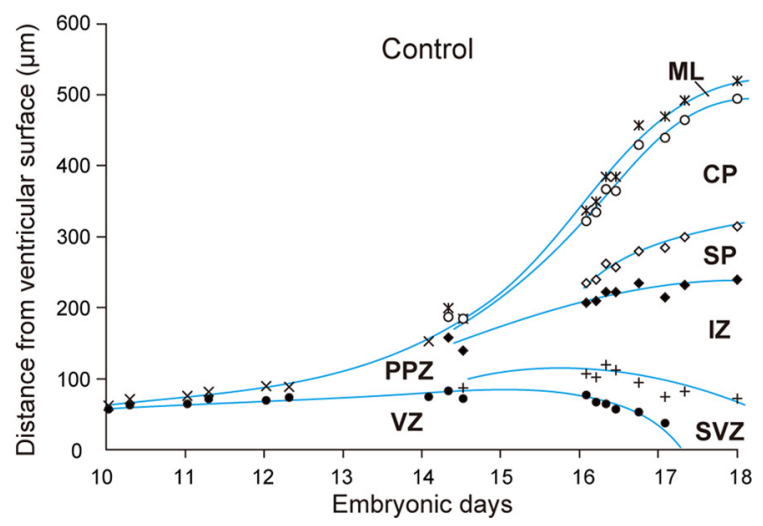

B
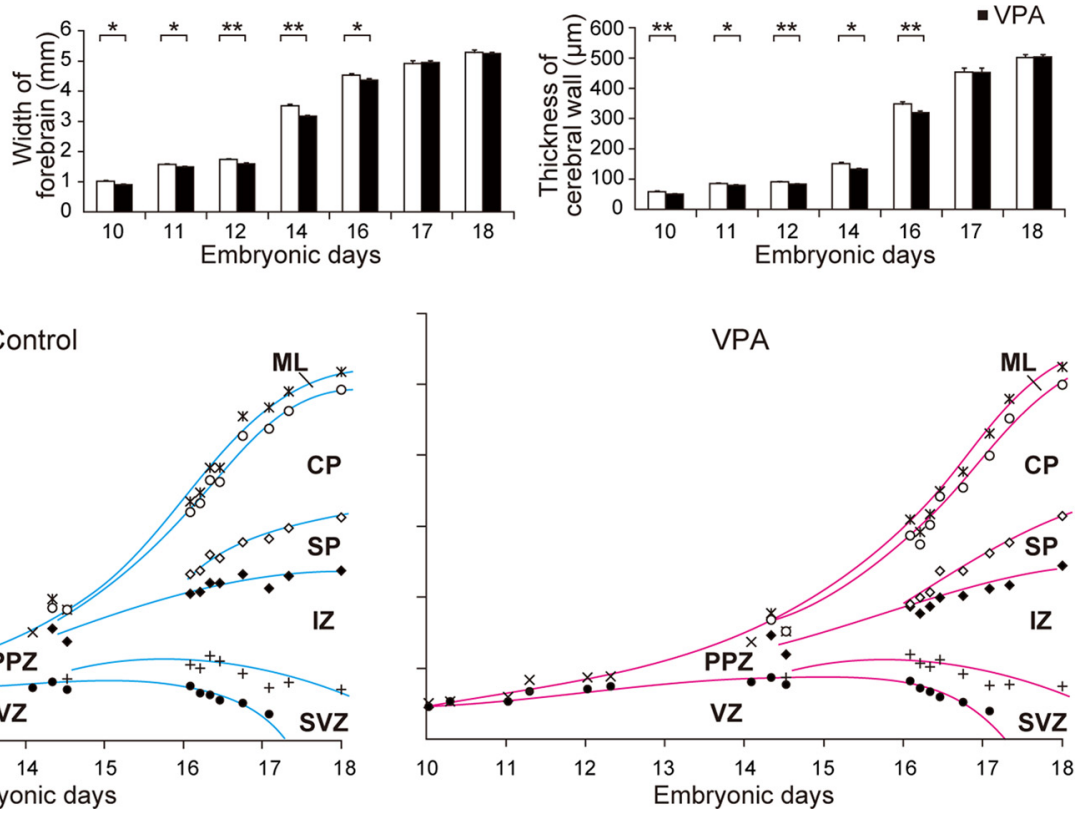

Figure 4. Effects of VPA exposure in utero on the structure of embryonic forebrains/telencephala. $A$, Low-magnification lateral views of controls and the VPA-exposed embryos on embryonic day 11 (E11). Scale bar, $1 \mathrm{~mm}$. B, The maximum mediolateral length (width) of forebrains/telencephala from E10 to E18. C, The thickness of dorsomedial cerebral walls from E10 to E18. D, Stratification of the dorsomedial cerebral walls from E10 to E18. The upper border of the ventricular zone (VZ), Closed circles; subventricular zone (SVZ), pluses; primitive plexiform zone (PPZ), X's; IZ, closed squares; subplate (SP), open squares; cortical plate (CP), open circles; molecular layer (ML), asterisks. Blue and red curves show approximate contours of each cortical layer for control and the VPA-exposed embryos, respectively. The cerebral walls comprised the VZ and a narrow overlying PPZ from E10 to early E14 in both groups. The PPZ was replaced by the SVZ, IZ, and cortical strata (SP, $(P$, and $\mathrm{ML})$ on $\mathrm{E} 14$ in both groups. The thickness of the VZ reached maximum on late E14 and then declined from E16 through E17 in both groups. ${ }^{*} p<0.05$; ${ }^{* *} p<0.01$. Error bars, SEM.

on day $10(n=8), 37.9 \pm 7.7 \mu \mathrm{g} / \mathrm{ml}$ on day $13(n=9)$, and $22.3 \pm$ $5.1 \mu \mathrm{g} / \mathrm{ml}$ on day 16 ( $n=9$; Fig. 1$)$. These concentrations were lower than the level that reportedly increased the seizure threshold by $50 \%$ in mice $(120-150 \mu \mathrm{g} / \mathrm{ml}$; Löscher, 1999), though marked variance was observed due to the short half-life of VPA in mice ( $<1$ h; Nau, 1985; Fig. 1). VPA exposure did not alter the body weight of the pregnant mothers on gestation day 12 (45.7 \pm 1.1 vs $47.4 \pm 3.0 \mathrm{~g}$ in controls; $p=0.622, n=4$ ) or the number of mice born from a single mother $(11.2 \pm 0.7$ vs $12.8 \pm 0.6$ mice in controls; $p=0.108, n=20$ ), compared with those in controls. The body weight of the VPA-exposed postnatal mice was decreased by $6.8 \%$, compared with that in controls, on P17 (11.8 \pm 0.2 vs $12.7 \pm 0.3 \mathrm{~g}$ in controls; $p=0.024, n=14)$. However, the body weights were not altered on P21 compared with controls $(16.3 \pm 0.3$ vs $16.8 \pm 0.2 \mathrm{~g}$ in controls; $p=0.111, n=32)$, though greater variance was observed in the VPA-exposed mice.

We did not detect any external malformations, such as macroscopic spina bifida, in the in utero VPA-exposed mice. The dorsomedial primary somatosensory area of the neocortices (field 1; Fig. 2A; Caviness, 1975) in the VPA-exposed mice comprised six layers, similar to that in controls (Fig. $2 B-D)$. No apparent differences were observed in the morphology of pyramidal neurons between the VPA-exposed mice and controls (Fig. 2E-G).

We measured the surface length of the telencephala as an index of the surface area, which approximately represents the tangential growth of the neocortices. The surface length of the telencephala was increased in the VPA-exposed mice by $4.6 \%$, compared with that in controls on P21 (7.69 \pm 0.10 vs $7.35 \pm$ $0.07 \mathrm{~mm}$ in controls; $p=0.012, n=8$ ). The full thickness of the neocortices (layers I-VI) and the thickness of the superficial layers (layers II-IV) were increased by $10.0 \%$ (781.8 \pm 11.4 vs $710.5 \pm 13.8 \mu \mathrm{m}$ in controls; $p=0.004, n=6)$ and $14.9 \%$
Table 1. Width of forebrains/telencephala in the mediolateral direction

\begin{tabular}{lllrr}
\hline & Control & VPA & \multicolumn{1}{l}{$p$} & $n$ \\
\hline E10 & $1.02 \pm 0.03 \mathrm{~mm}$ & $0.90 \pm 0.03 \mathrm{~mm}$ & 0.011 & 9 \\
E11 & $1.58 \pm 0.02 \mathrm{~mm}$ & $1.49 \pm 0.03 \mathrm{~mm}$ & 0.020 & 12 \\
E12 & $1.74 \pm 0.03 \mathrm{~mm}$ & $1.60 \pm 0.03 \mathrm{~mm}$ & 0.002 & 9 \\
E14 & $3.52 \pm 0.06 \mathrm{~mm}$ & $3.17 \pm 0.04 \mathrm{~mm}$ & $<0.001$ & 12 \\
E16 & $4.53 \pm 0.06 \mathrm{~mm}$ & $4.37 \pm 0.05 \mathrm{~mm}$ & 0.040 & 11 \\
E17 & $4.92 \pm 0.09 \mathrm{~mm}$ & $4.95 \pm 0.06 \mathrm{~mm}$ & 0.742 & 8 \\
E18 & $5.28 \pm 0.09 \mathrm{~mm}$ & $5.25 \pm 0.04 \mathrm{~mm}$ & 0.706 & 8 \\
\hline
\end{tabular}

Values are shown as mean \pm SEM.

Table 2. Thickness of the dorsomedial cerebral walls

\begin{tabular}{llllr}
\hline & Control & VPA & $p$ & $n$ \\
\hline E10 & $59.2 \pm 1.7 \mu \mathrm{m}$ & $50.8 \pm 1.8 \mu \mathrm{m}$ & 0.004 & 9 \\
E11 & $86.2 \pm 2.0 \mu \mathrm{m}$ & $80.3 \pm 1.8 \mu \mathrm{m}$ & 0.037 & 12 \\
E12 & $91.2 \pm 2.0 \mu \mathrm{m}$ & $83.5 \pm 1.5 \mu \mathrm{m}$ & 0.006 & 9 \\
E14 & $151.4 \pm 5.5 \mu \mathrm{m}$ & $132.8 \pm 4.0 \mu \mathrm{m}$ & 0.012 & 12 \\
E16 & $348.2 \pm 7.5 \mu \mathrm{m}$ & $319.8 \pm 6.6 \mu \mathrm{m}$ & 0.009 & 11 \\
E17 & $454.1 \pm 13.1 \mu \mathrm{m}$ & $455.0 \pm 14.2 \mu \mathrm{m}$ & 0.961 & 8 \\
E18 & $501.8 \pm 9.6 \mu \mathrm{m}$ & $503.5 \pm 8.1 \mu \mathrm{m}$ & 0.894 & 8 \\
\hline
\end{tabular}

Values are shown as mean \pm SEM.

$(331.8 \pm 6.4$ vs $288.7 \pm 6.5 \mu \mathrm{m}$ in controls; $p=0.001, n=6)$, respectively, in the VPA-exposed mice, compared with those in controls on P21 (Fig. 3A). In contrast, the thickness of the deeper layers (layers $\mathrm{V}$ and $\mathrm{VI}$ ) was not significantly different between the two groups $(383.3 \pm 14.0$ vs $362.5 \pm 10.8 \mu \mathrm{m}$ in controls; $p=$ $0.290, n=6$; Fig. $3 A$ ). These results were consistent with the results of immunohistochemical staining for Cux1, a marker for the superficial layer neurons, and CTIP2, a marker for the deeper layer neurons (Fig. 2D). 
A

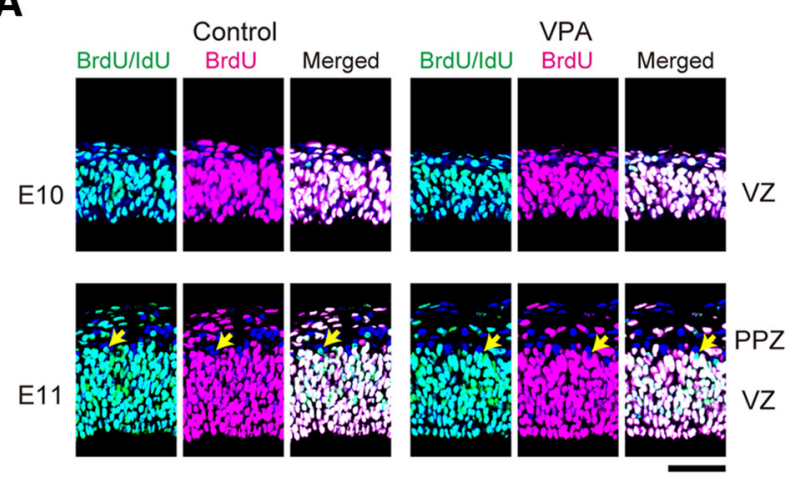

B

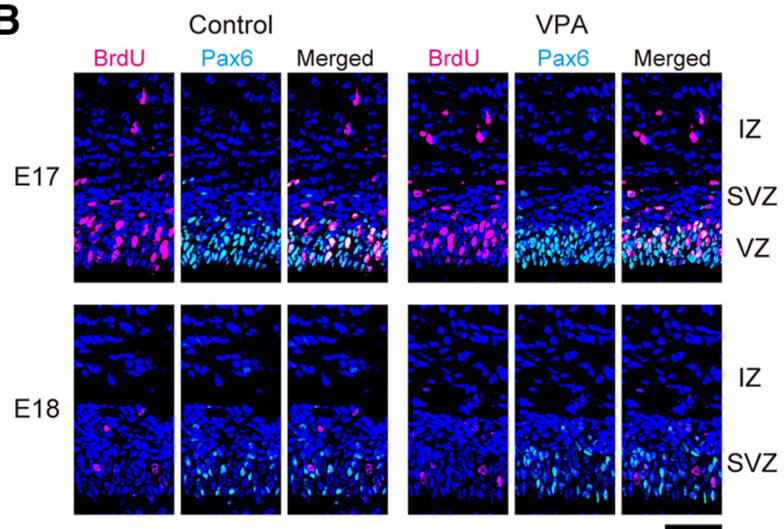

C
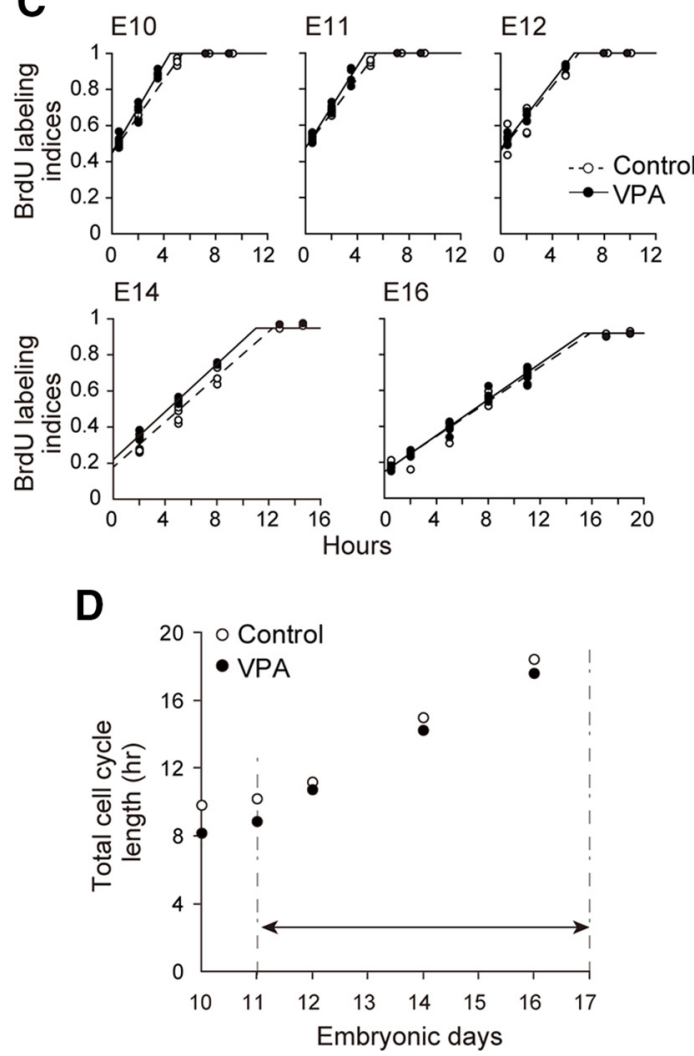

Figure 5. Effects of in utero VPA exposure on the neuronogenetic period and the cell cycle lengths of the neural progenitor cells (NPCs) in the VZ. A, Dorsomedial cerebral walls in Q experiments on E10 and E11. Green, IdU/BrdU-positive nuclei; red, BrdU-positive nuclei; blue, Hoechst 33352 counter-stained nuclei; white, green/red double-positive nuclei. Yellow arrows indicate IdU-positive/ BrdU-negative nuclei that correspond to the postmitotic cells that exited from the cell cycle ( $Q$ cells) on the corresponding day. Scale bar, $50 \mu \mathrm{m}$. $\boldsymbol{B}$, Dorsomedial cerebral walls after a $2 \mathrm{~h}$ BrdU exposure on early E17 and E18, double stained for BrdU and Pax6. Red, BrdU-positive nuclei; light blue, Pax6-expressing progenitor cells; blue, Hoechst 33352 counter-stained nuclei. Scale bar, 50 $\mu \mathrm{m}$. C, Progression of BrdU labeling indices in the VZ with cumulative BrdU labeling conducted on E10, E11, E12, E14, and E16. The dashed and continuous lines are regression lines of the plotted labeling indices of controls and the VPA-exposed embryos, respectively. D, The total cell cycle lengths on E10, E11, E12, E14, and E16. The bidirectional arrow between the two dot chain lines indicates the neuronogenetic interval in the VZ (i.e., from E11 to E17).

VPA exposure in utero increased the number of non-GABAergic projection neurons in the superficial layers of the P21 neocortices

VPA exposure in utero increased the number of non-GABAergic projection neurons by $13.9 \%$ ( $431.6 \pm 7.0$ vs $378.9 \pm 8.0$ cells per counting area in controls; $250 \mu \mathrm{m}$ in width and the total neocortical thickness in height; $p<0.001, n=6$ ) in field 1 of the neocortices on P21, compared with that in controls (Fig. $3 B$ ). This increase was caused solely by a $21.1 \%$ increase in the number of non-GABAergic projection neurons in the superficial layers $(219.3 \pm 5.9$ vs $181.1 \pm 7.4$ cells in controls; $p=0.004, n=6)$; no significant difference was observed in the deeper layers $(211.1 \pm$ 5.4 vs $196.8 \pm 4.3$ cells in controls; $p=0.074, n=6$; Fig. $3 B$ ). Further, analysis using a linear mixed-effects model showed a significant interaction between the increased number of nonGABAergic neurons and the superficial layers in the VPAexposed mice $(p=0.004, n=6)$. The numbers of GABAergic interneurons $(28.2 \pm 1.1$ vs $26.4 \pm 1.4$ cells in controls; $p=0.389$, $n=6)$ and glial cells ( $44.9 \pm 3.1$ vs $43.1 \pm 2.0$ cells in controls; $p=0.638, n=6$ ), or their distribution patterns were not different between the two groups (Fig. $3 C-E$ ).

VPA exposure in utero decreased the size of the forebrains/ telencephala during the early development of the neocortices When measured on E11, VPA exposure decreased (1) the crown-rump length by $7.2 \%$ (5.67 \pm 0.06 vs $6.11 \pm 0.09 \mathrm{~mm}$
Table 3. Cell cycle phase durations of the NPCs in the VZ

\begin{tabular}{|c|c|c|c|c|c|c|c|c|}
\hline & \multicolumn{4}{|c|}{ Control } & \multicolumn{4}{|l|}{ VPA } \\
\hline & $T_{C}$ & $T_{S}$ & $T_{G 1}$ & $T_{G 2+M}$ & $T_{C}$ & $T_{S}$ & $T_{G 1}$ & $T_{G 2+M}$ \\
\hline E10 & $9.8 \mathrm{~h}$ & $4.4 \mathrm{~h}$ & $3.4 \mathrm{~h}$ & $2.0 \mathrm{~h}$ & $8.2 \mathrm{~h}$ & $3.7 \mathrm{~h}$ & $2.5 \mathrm{~h}$ & $2.0 \mathrm{~h}$ \\
\hline E11 & $10.2 \mathrm{~h}$ & $4.8 \mathrm{~h}$ & $3.4 \mathrm{~h}$ & $2.0 \mathrm{~h}$ & $8.9 \mathrm{~h}$ & $4.2 \mathrm{~h}$ & $2.7 \mathrm{~h}$ & $2.0 \mathrm{~h}$ \\
\hline E12 & $11.2 \mathrm{~h}$ & $5.2 \mathrm{~h}$ & $4.0 \mathrm{~h}$ & $2.0 \mathrm{~h}$ & $10.8 \mathrm{~h}$ & $5.1 \mathrm{~h}$ & $3.7 \mathrm{~h}$ & $2.0 \mathrm{~h}$ \\
\hline E14 & $15.0 \mathrm{~h}$ & $2.7 \mathrm{~h}$ & $10.3 \mathrm{~h}$ & $2.0 \mathrm{~h}$ & $14.3 \mathrm{~h}$ & $3.2 \mathrm{~h}$ & $9.1 \mathrm{~h}$ & $2.0 \mathrm{~h}$ \\
\hline E16 & $18.4 \mathrm{~h}$ & $2.8 \mathrm{~h}$ & $13.6 \mathrm{~h}$ & $2.0 \mathrm{~h}$ & $17.6 \mathrm{~h}$ & $2.6 \mathrm{~h}$ & $13.0 \mathrm{~h}$ & $2.0 \mathrm{~h}$ \\
\hline
\end{tabular}

$T_{C}$, the length of the total cell cycle; $T_{S}, S$-phase; $T_{G 1}, G 1$-phase; $T_{G 2}+M, G 2+M$-phase.

in controls; $p<0.001, n=15)$ and (2) the rostrocaudal length of the forebrains by $10.0 \%(1.31 \pm 0.02$ vs $1.46 \pm 0.03$ $\mathrm{mm}$ in controls; $p<0.001, n=15)$, compared with those in controls (Fig. 4A). The maximum mediolateral length (width) of the forebrains/telencephala was decreased by 3.7$11.7 \%$ in the VPA-exposed embryos on E10, E11, E12, E14, and E16, compared with that in controls, whereas the width was equivalent between the two groups on E17 and E18 (Fig. $4 B$; Table 1).

The thickness of the cerebral walls was decreased by $6.9-$ $14.2 \%$ in the VPA-exposed embryos, compared with those in controls, on E10, E11, E12, E14, and E16, while the thickness was equivalent between the two groups on E17 and E18 (Fig. 4C; Table 2). The layer structure of the cerebral walls was not different between the two groups (Fig. 4D). 

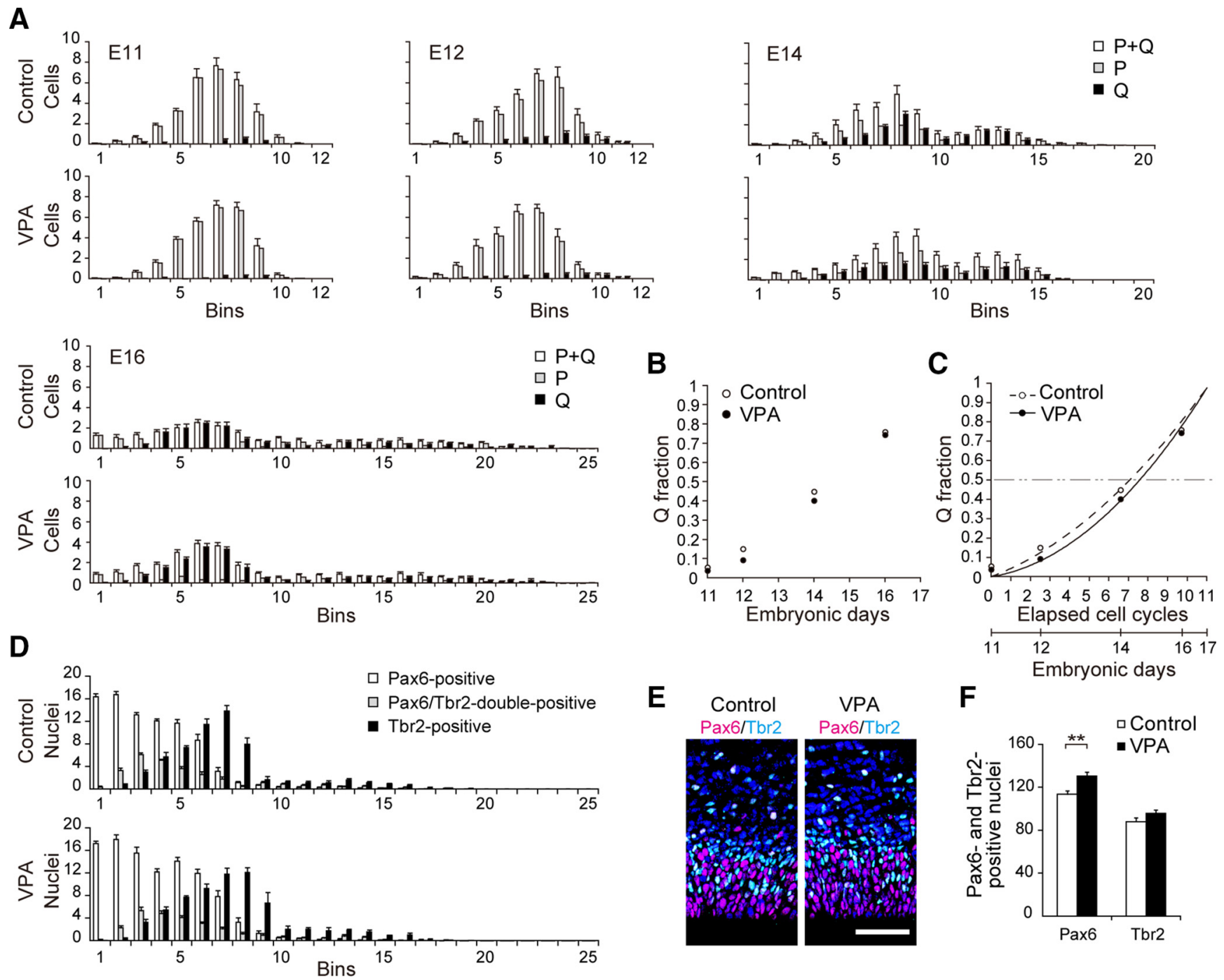

Figure 6. Effects of VPA exposure in utero on the proliferation/differentiation characteristics of the NPCs. A, Distribution of the daughter cells ( $P+Q$ cells), proliferative NPCs (P cells), and Q cells within the dorsomedial cerebral walls on E11, E12, E14, and E16. The cells were counted in each bin (100 $\mu \mathrm{m}$ in width and $10 \mu \mathrm{m}$ in height) lined serially from the ventricular surface to the pia of the dorsomedial cerebral walls. $B$, The $Q$ fractions on E11, E12, E14, and E16. C, The $Q$ fractions against estimated elapsed cell cycles. Regression curves of the $Q$ fractions were based on the neuronogenetic interval shown in Fig. $5 A, B$, in which the $Q$ fractions were considered to be 0 and 1 on $E 11$ and E17, respectively. Dashed curve, Regression curve of the $Q$ fraction in controls: $Q_{(t)}=$ $0.0046 t^{2}+0.0381 t, r^{2}=0.9908$; continuous curve, regression curve of the $Q$ fraction in the VPA-exposed embryos: $Q_{(t)}=0.0066 t^{2}+0.0160 t, r^{2}=0.9954 ; t$, number of elapsed cell cycles from the onset of neuronogenesis. The two dot chain line shows $Q=0.5$. D. The number of Pax6-positive, Pax6/Tbr2-double-positive, and Tbr2-positive nuclei within the cerebral wall on E16. $E$, Dorsomedial cerebral wall stained for Pax6 and Tbr2. Red, Pax6-positive nuclei (color tone adjusted to red for visibility); light blue, Tbr2-positive nuclei; blue, Hoechst 33352 counter-stained nuclei. Scale bar, $50 \mu \mathrm{m} . \boldsymbol{F}$, Total number of Pax6-positive and Tbr2-positive nuclei. ${ }^{* *} p<0.01$. Error bars, SEM.

VPA exposure in utero did not modify the length of neuronogenetic period or the total number of cell divisions of NPCs in the VZ

Newly produced neurons, identified as mitotically quiescent (Q) cells, were identified only on and after E11, but not on E10, both in the VPA-exposed embryos and in controls (Fig. 5A; Takahashi et al., 1996b). Further, the ventricular zone (VZ), defined as a homogeneous pseudostratified ventricular epithelium in which the nuclei show interkinetic nuclear movement (Bystron et al., 2008), disappeared and was displaced by the subventricular zone (SVZ) during E17 in both groups (Fig. 5B; Takahashi et al., 1995b; Englund et al., 2005), indicating the termination of the neuronogenetic period within the VZ. Namely, the neuronogenetic period in the VZ lasted for $6 \mathrm{~d}$ both in the VPA-exposed embryos and in controls. The $T_{C}$ of the NPCs in the VZ was not different between the two groups on E10, E11, E12, E14, and E16 (Fig. 5C,D; Table 3). Thus, the total number of cell divisions of the NPCs was $\sim 11$ cycles in both groups.
Table 4. The numbers of $P+Q$ and $Q$ cells and the values of $P$ and $Q$ fractions

\begin{tabular}{|c|c|c|c|c|c|c|c|c|}
\hline & \multicolumn{4}{|l|}{ Control } & \multicolumn{4}{|l|}{ VPA } \\
\hline & $N_{P+Q}$ & $N_{0}$ & $P$ & 0 & $N_{\mathrm{P}+\mathrm{Q}}$ & $N_{Q}$ & $P$ & Q \\
\hline E10 & $\mathrm{N} / \mathrm{A}$ & 0.00 & 1.00 & 0.00 & NA & 0.00 & 1.00 & 0.00 \\
\hline E11 & 30.56 & 1.65 & 0.95 & 0.05 & 29.65 & 1.09 & 0.96 & 0.04 \\
\hline $\mathrm{E} 12$ & 29.06 & 4.41 & 0.85 & 0.15 & 28.91 & 2.66 & 0.91 & 0.09 \\
\hline E14 & 18.80 & 8.43 & 0.55 & 0.45 & 20.08 & 8.05 & 0.60 & 0.40 \\
\hline E16 & 13.67 & 10.36 & 0.24 & 0.76 & 17.08 & 12.69 & 0.26 & 0.74 \\
\hline
\end{tabular}

VPA exposure in utero increased the maximum number of NPCs by decreasing the probability of cell cycle exit

( $Q$ fraction) during the early-middle neuronogenetic period

To investigate the effect of VPA exposure in utero on the proliferation/differentiation profiles of the NPCs in the VZ, we analyzed the probability of cell cycle exit ( $Q$ fraction) for a 


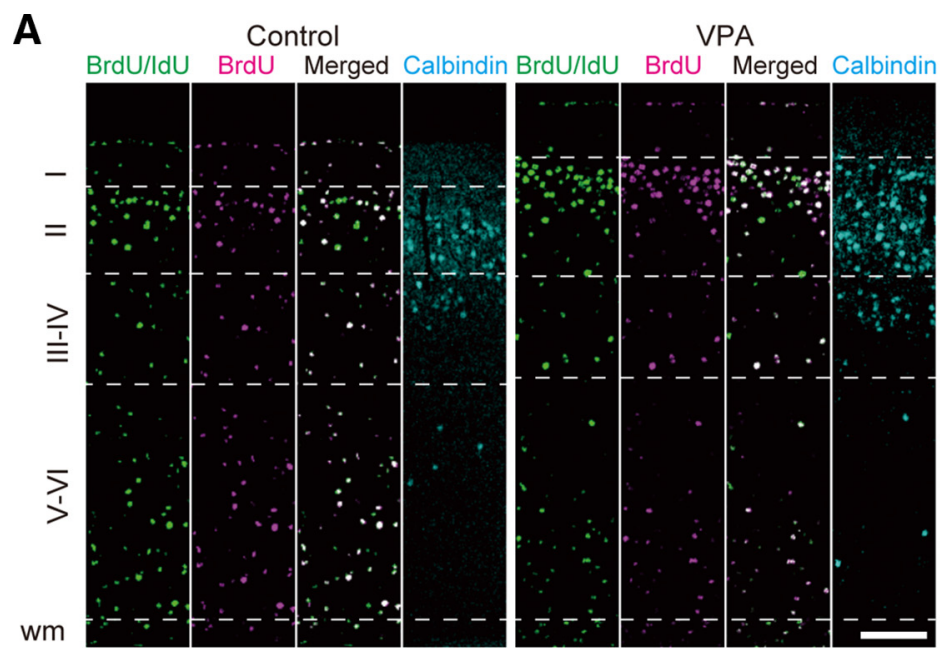

B
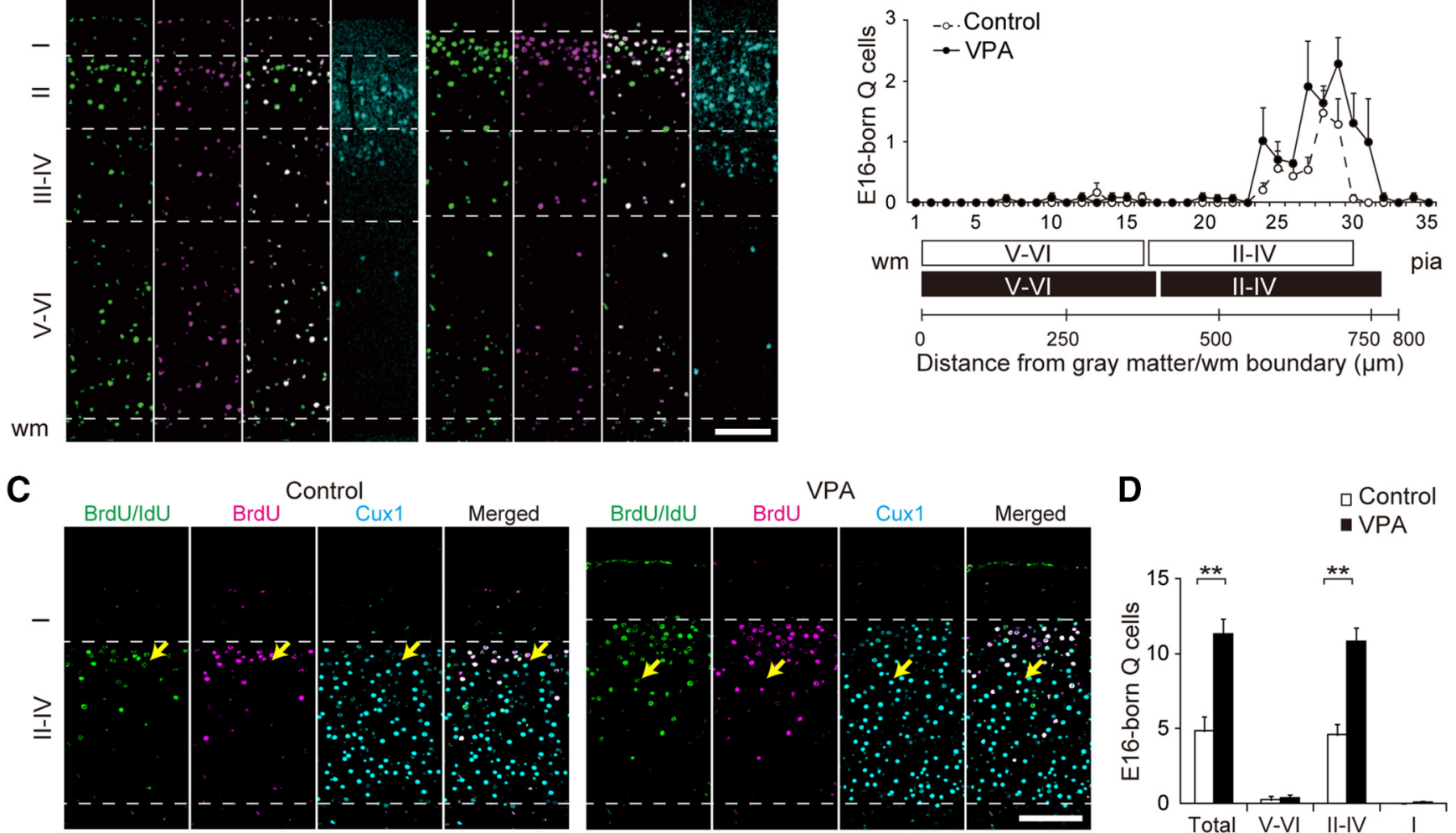

Figure 7. Effects ofVPA exposure in utero on the number and distribution of neurons born on E16.A, The neocortical field 1 on P21 after Q experiment conducted on E16. Green, IdU/BrdU-positive nuclei; red, BrdU-positivenuclei; white, green/red double-positive nuclei; blue, calbindin-positiveneurons that correspond to neurons distributed in layer Il of the neocortices. IdU-positive/BrdU-negativenuclei labeled only with green correspond to theneurons born on E16 (E16-born Q cells). White dashed lines, Boundaries between neocortical layers//IIII/III-IV, III-IV/N-VI, and gray matter/wm. Scalebar, $100 \mu \mathrm{mm}$. B, Thenumber of E16-born Q cells counted in each bin ( $250 \mu \mathrm{m}$ in width; $25 \mu \mathrm{m}$ in height) lined serially from the wm to the pia in the neocortical field 1 shown in $A$. White and black boxes under the abscissa indicate layers V-VI/II-IV in the neocortices of controls and the VPA-exposed mice, respectively. C, The superficial layers of neocortical field 1 triple stained for IdU, BrdU, and Cux1. Green, IdU/BrdU-positive nuclei; red, BrdU-positive nuclei; blue, Cux1-positive superficial neurons. The yellow arrows indicate the E16-born Cux1-positive superficial neurons. Note that the E16-born Q cells were mainly Cux1-positive. Scale bar, 100 $\mu \mathrm{m} . \boldsymbol{D}$, The number of E16-born Q cells in representative neocortical layers. Counting areas, $250 \mu \mathrm{m}$ in width and the total neocortical thickness in height. ${ }^{* *} p<0.01$. Error bars, SEM.

quantitative analysis labeling $2 \mathrm{~h}$ cohort of the NPCs (Takahashi et al., 1996b). The distribution pattern of the proliferative NPCs ( $P$ cells) and Q cells within the cerebral walls were almost identical between the VPA-exposed embryos and controls (Fig. 6A). However, the $\mathrm{Q}$ fraction, calculated as the number of $\mathrm{Q}$ cells divided by the number of $\mathrm{P}+\mathrm{Q}$ cells, was significantly decreased in the VPA-exposed embryos on E11, E12, and E14, while it was identical between the two groups on E16 (Fig. 6B; Table 4; Takahashi et al., 1996b).

The number of NPC divisions before the Q fraction reached 0.5, the critical parameter for the maximum size of the NPC population, increased in the VPA-exposed embryos ( 7.6 vs 7.1 cycles in controls; Fig. 6C). This indicates an augmented expansion of the NPC population during the early and middle phase of neuronogenesis (when $Q$ is $<0.5$ ) and increased neuronal production destined for the superficial layers during the latter phase (when $Q$ is $>0.5$; Takahashi et al., 1996b, 1999). Indeed, the total number of nuclei that were positive for Pax6, a transcription factor expressed in the NPCs of the VZ, was increased on E16 in the VPA-exposed embryos by 15.0\% compared with controls ( $130.5 \pm 3.6$ vs $113.5 \pm 3.3$ nuclei per counting area in controls; $100 \mu \mathrm{m}$ in width and the total thickness of the VZ, SVZ, and intermediate zone (IZ) in height; $p=0.006, n=6$; Fig. $6 D-F$ ). However, the total number of nuclei that were positive for Tbr2, a transcription factor expressed in the basal progenitor cells (BPs) of the SVZ, was not different between the two groups on E16 (95.8 \pm
3.1 vs $88.0 \pm 3.6$ nuclei per counting area in controls; $100 \mu \mathrm{m}$ in width and the total thickness of the VZ, SVZ, and IZ in height; $p=$ 0.135, $n=6$; Fig. $6 D-F)$.

To investigate the effects of the altered pattern of $Q$ fraction ascent by VPA exposure in utero on neuronal production during the latter phase of neuronogenesis, we analyzed the distribution and the number of Q cells "born" on E16 in neocortical field 1 at $\mathrm{P} 21$. The E16-born Q cells distributed normally in layer II of the P21 neocortices (Fig. 7A,B) and were positive for Cux1 in both groups (Fig. 7C). However, the number of these E16-born Q cells was increased by $134 \%$ by VPA exposure $(11.3 \pm 0.9$ vs $4.8 \pm 0.8$ cells per counting area in controls; $250 \mu \mathrm{m}$ in width and the total thickness of neocortices in height; $p=0.003, n=4$; Fig. $7 B, D)$.

\section{VPA exposure in utero increased the number of neurons in} the superficial layers of the neocortices on $\mathrm{P} 4$

We investigated neocortical architecture on P4 to confirm that the enhanced neocortical thickness in VPA-exposed mice was a result of increased neuronal production rather than overgrowth of the neuropil. Rapid growth of the neuropil takes place after P4 by glial proliferation and synapse formation, and thus the neocortical architecture of P4 directly reflects the production and distribution of projection neurons (Takahashi et al., 1996a).

VPA exposure in utero increased the total neocortical thickness by $10.4 \%$ on $\mathrm{P} 4$ (516.2 \pm 4.3 vs $467.8 \pm 7.9 \mu \mathrm{m}$ in controls; 
A
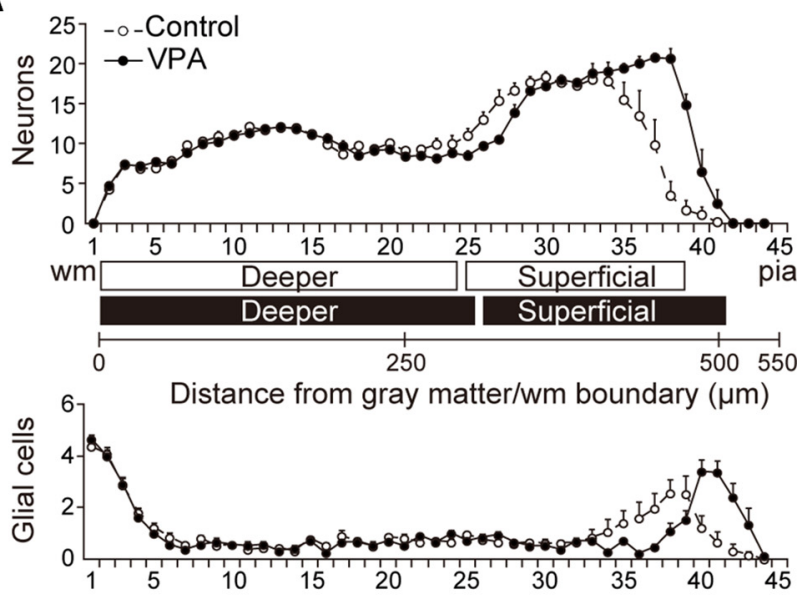

B

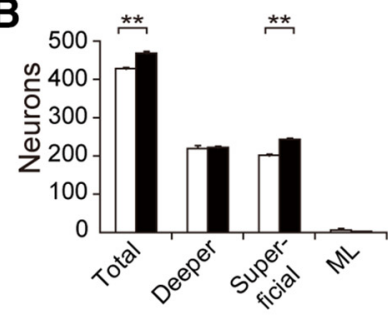

C

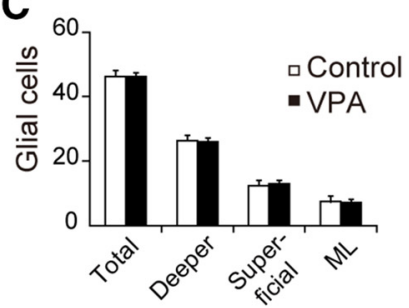

D
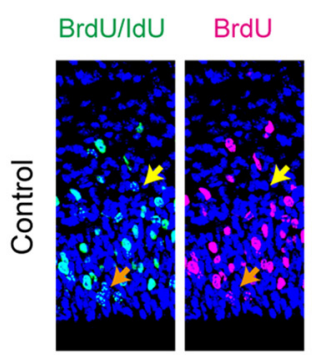

One-hou
cohort
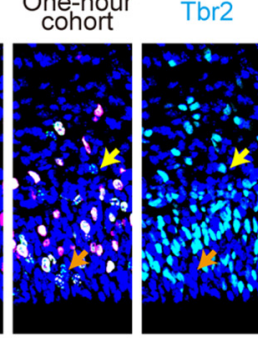

Merged
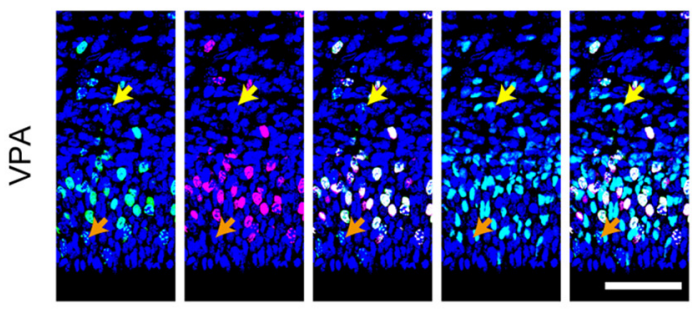

E

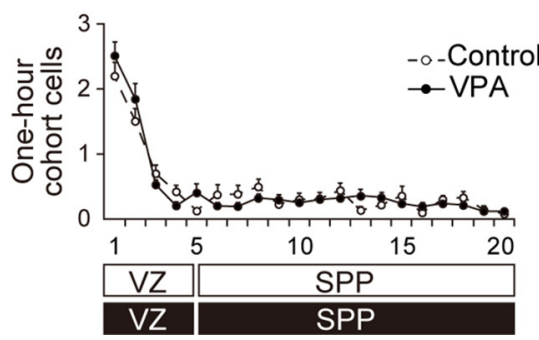

Figure 8. Effects of VPA exposure in utero on the histological architecture of the neocortices on P4, and the distribution of the secondary proliferative population (SPP) on E16. $\boldsymbol{A}$, The numbers of neurons (which included both non-GABAergic projection neurons and GABAergic interneurons) and glial cells counted in each bin ( $125 \mu \mathrm{m}$ in width and $12.5 \mu \mathrm{m}$ in height) lined serially from the wm to the pia in field 1 of the neocortices. White and black boxes under the abscissa indicate deeper/superficial layers (future layers V-VI/II-IV) defined by the bimodal distribution of the neurons in the neocortices of controls and the VPA-exposed mice, respectively. $\boldsymbol{B}$, The number of neurons in representative neocortical layers. Counting areas, $125 \mu \mathrm{m}$ in width and the total neocortical thickness in height. Analysis using a linear $p<0.001, n=8)$. The number of neurons in the VPA-exposed mice was increased by $20.9 \%$ in the superficial layers (future layers II-IV; $243.3 \pm 3.6$ vs $201.2 \pm 7.7$ cells per counting area in controls; $125 \mu \mathrm{m}$ in width and the total neocortical thickness in height; $p<0.001, n=8$ ), while it was not altered in the deeper layers (future layers V and VI; $221.8 \pm 4.0$ vs $219.8 \pm 6.9$ cells in controls; $p=0.798, n=8$ ) on P4 (Fig. $8 A, B$ ). Analysis using a linear mixed-effects model showed a significant interaction between the increased number of neurons and the superficial layers in the VPA-exposed mice $(p<0.001, n=8)$. There were no differences in the number of glial cells $(46.3 \pm 1.2$ vs $46.3 \pm 1.9$ cells per counting area in controls; $p=1.000, n=8$; Fig. $8 C$ ), in the overall densities of neurons, or in the surface length of the telencephala $(4.64 \pm 0.04$ vs $4.68 \pm 0.05 \mathrm{~mm}$ in controls; $p=$ $0.553, n=8$ ) between the two groups on $\mathrm{P} 4$.

VPA exposure in utero leads neither to the altered cell cycle kinetics of secondary proliferative population nor to the increased occurrence of apoptosis

We analyzed the cell cycle kinetics of the secondary proliferative population (SPP), since the SPP might be involved in the production of the superficial neocortical neurons (Boulder Committee, 1970; Takahashi et al., 1995b; Miyama et al., 1997; Götz and Huttner, 2005; Bystron et al., 2008; Kowalczyk et al., 2009). VPA exposure in utero did not alter the following indices of the SPP on E16, compared with those in controls: (1) the $T_{C}(13.9 \mathrm{vs} 14.0 \mathrm{~h}$ in controls), (2) the distribution pattern in the cerebral wall (Fig. $8 D, E)$, and (3) the size of population $(52.4 \pm 6.7$ vs $59.7 \pm 9.5$ cells per counting area in controls; $100 \mu \mathrm{m}$ in width and the total thickness of cerebral walls in height; $p=0.544, n=9)$. Additionally, the number of BrdU-positive nuclei was not different between the two groups after a $2 \mathrm{~h}$ exposure to BrdU on E18 (34.4 \pm 1.2 vs $31.5 \pm 0.8$ nuclei per counting area in controls; $100 \mu \mathrm{m}$ in width and the total thickness of the SVZ and IZ in height; $p=$ $0.065, n=8$ ), indicating that the population size of the SPP after the disappearance of the VZ was not altered by VPA exposure in utero.

The number of TUNEL-positive neurons was not different between the two groups in the neocortices on P4 ( $1.40 \pm 0.18$ vs $1.48 \pm 0.16$ cells per counting area in controls; $125 \mu \mathrm{m}$ in width and the total neocortical thickness in height; $p=0.757, n=15$ ), at which the apoptotic activity had reached its maximum in the murine neocortices (Verney et al., 2000). Additionally, no difference in the number of pyknotic nuclei was detected in the embryonic cerebral walls between the two groups.

VPA exposure in utero increased the amount of cell cycle regulatory proteins and total acetylated histone $\mathrm{H} 3$ protein in NPCs

VPA exposure in utero increased the amount of cell cycle regulatory proteins cyclinD1, cyclin-dependent kinase (cdk)2, cdk4,

mixed-effects model showed a significant interaction between the increase in the number of neurons and the superficial layers shown in $\boldsymbol{A}$ in the VPA-exposed mice $(p<0.001)$. C, The number of glial cells. $\boldsymbol{D}$, Dorsomedial cerebral walls after $1 \mathrm{~h}$ cohort analysis conducted on E16. Green, IdU/BrdU-positive nuclei; red, BrdU-positive nuclei; blue, Tbr2-expressing basal progenitor cells (BPs). The $1 \mathrm{~h}$ cohort nuclei in the $\mathrm{G} 2$ and $\mathrm{M}$ phases were separated into progenitors of the VZ (orange arrow) and SPP (yellow arrow). Note the majority, but not all, of the SPP progenitors were expressing Tbr2. Scale bar, $50 \mu \mathrm{m}$. E, The number of IdU-positive/BrdU-negative $1 \mathrm{~h}$ cohort nuclei counted in each bin (100 $\mu \mathrm{m}$ in width and $10 \mu \mathrm{m}$ in height) lined serially from the ventricular surface to the IZ. White and black boxes under the abscissa indicate the distribution of $1 \mathrm{~h}$ cohort cells of VZ/SPP of controls and the VPA-exposed embryos, respectively. ${ }^{* *} p<0.01$. Error bars, SEM. 
A

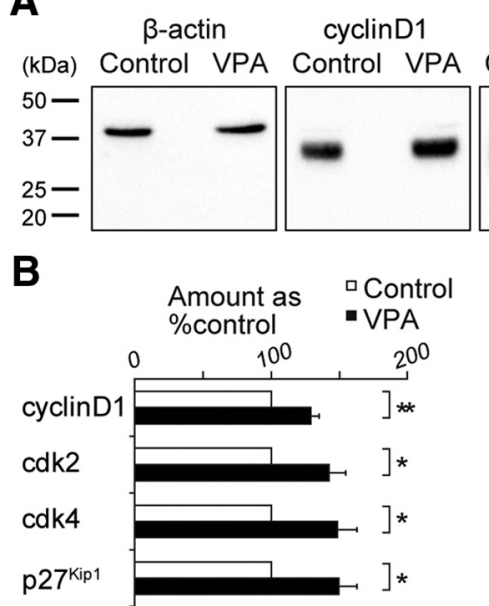

cdk2

cdk4 p27 $\quad$ kip1 Control VPA Control VPA Control VPA

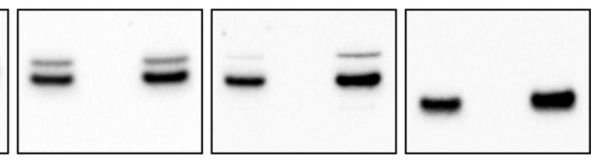

C

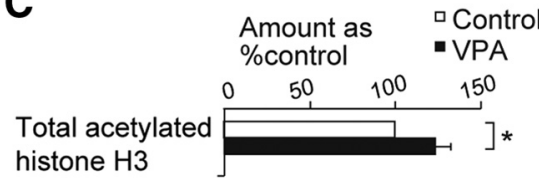

Figure 9. Effects of VPA exposure in utero on the amount of cell cycle regulatory proteins and total acetylated histone $\mathrm{H} 3$ protein in the embryonic cerebral walls. A, Immunoblot analysis of cyclinD1, cyclin-dependent kinase (cdk) 2, cdk4, and p27 Kip1 in cerebral walls on E12. B. The amount of each protein in controls was considered to be $100 \%$. C, The amount of total acetylated histone H3 protein in cerebral walls on E12. ${ }^{*} p<0.05 ;{ }^{* *} p<0.01$. Error bars, SEM.

A

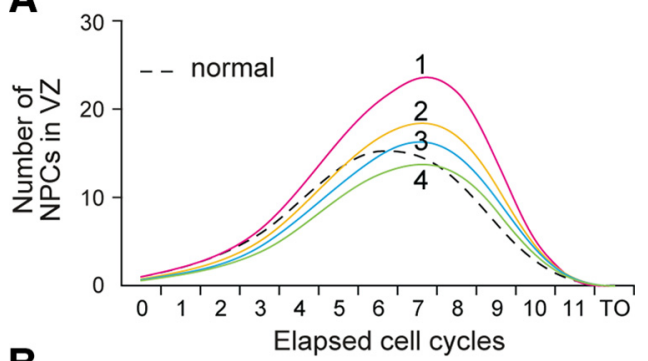

B

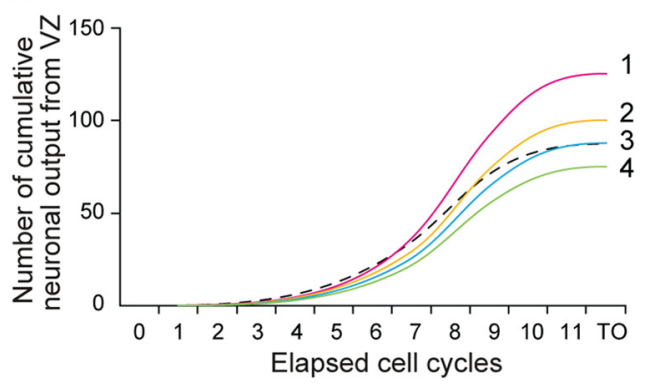

Figure 10. Assumption models of the numbers of NPCS and the neuronal output during the neuronogenetic interval in the VZ.A, The number of NPCs from cell cycle number 1 to terminal output (TO) were calculated from the regression curves of the normal and altered ascending patterns of $Q$ fractions shown in Fig. $6 C$ ( from controls and the VPA-exposed embryos, respectively). The number of NPCs at the onset of neuronogenesis (initial NPC number) in the normal model was assumed to be one. Black dashed line, Normal model. Red (altered Q fraction model 1), orange (model 2), blue (model 3 ), and green lines (model 4) show altered $Q$ fraction models when the initial NPC number was reduced by $0,20,30$, and $40 \%$, respectively, compared with the normal model. The maximum numbers of NPCs in the altered Q fraction models were calculated as 55,24 , and $8 \%$ increases, and a $7 \%$ decrease in models 1, 2, 3, and 4, respectively, compared with the normal model. The models show that $\mathrm{Q}$ fraction alteration can increase the maximum number of NPCs in the VZ, depending on the extent of the reduction in initial NPCS. $\boldsymbol{B}$, The cumulative neuronal output from the NPCs in the VZ as calculated in $\boldsymbol{A}$. The total neuronal outputs in the altered $Q$ fraction models were calculated as $44 \%$ increase, $15 \%$ increase, no change, and 14\% decrease, in models 1,2,3, and 4, respectively, compared with the normal model. The models show that $Q$ fraction alteration can increase the cumulative neuronal output from the VZ depending on the extent of the reduction in initial NPCS.

and $\mathrm{p} 27^{\mathrm{Kip} 1}$ within the nuclear fractions of the NPCs by $30 \%-$ $50 \%$ on $\mathrm{E} 12$ ( $n=3$; Fig. $9 A, B)$, and increased the amount of total acetylated histone $\mathrm{H} 3$ protein extracted from $\mathrm{E} 12$ embryonic ce- rebral walls by $23 \pm 9 \%$ compared with controls ( $p=0.044, n=4$; Fig. 9C).

\section{Discussion}

VPA exposure in utero more than doubled the number of E16-born neurons distributed in the superficial layers of the neocortices (Fig. 7D). Additionally, VPA exposure in utero increased the amounts of acetylated histone proteins and G1phase regulatory proteins in the embryonic cerebral walls (Fig. $9 A-C$ ) and inhibited NPC differentiation during the early to middle phases of neuronogenesis (Fig. 6B,C). Our findings are compatible with previous reports finding that (1) VPA exposure in utero increases the neocortical thickness both in humans (Wood et al., 2014) and rats (Sabers et al., 2014), and (2) VPA exposure to cultured mice embryonic stem cells increased the production of superficial neocortical neurons (Juliandi et al., 2012). The administration regimen used in our study, i.e., low-dose VPA administration throughout the pregnancy, resulted in plasma concentrations lower than those needed to increase the seizure threshold in mice (Löscher, 1999); our administration regimen resembles that for pregnant women with epilepsy and better represents the pathology in human embryos than previous reports.

\section{Mechanisms of neocortical dysgenesis by VPA exposure in utero}

VPA exposure in utero modified the ascending pattern of the $\mathrm{Q}$ fraction (Fig. $6 B, C$ ) without altering the onset or the end of neuronogenesis or the total number of NPC divisions in the VZ. The Q alteration increased the number of NPC division cycles before $Q$ reached 0.5 ( $\sim$ E11-E14; Fig. $6 C$ ) and thus increased the peak population size of the NPCs and subsequent neuronal production, leading to neocortical thickening (Fig. 10A,B; Takahashi et al., 1996b, 1999).

NPC proliferation during the early to middle phases of neuronogenesis leads to tangential expansion of the VZ, which increases the number of ontogenic columns according to the radial unit hypothesis (Rakic, 1988; Jones and Rakic, 2010). The increased neocortical surface area in the VPA-exposed mice suggests a greater number of ontogenic columns due to augmented NPC proliferation. Contrary to a previous in vitro study, the number of deeper layer neurons was not decreased by VPA exposure in utero in the present study, suggesting that the abnormally increased NPC population was able to produce deeper layer neurons even with the inhibition of NPC differentiation, during the early to middle phases of neuronogenesis (Figs. 2B,D, 3B; Juliandi et al., 2012).

Some of the NPCs continue to divide after exiting the VZ, giving rise to projection neurons and glial cells (Boulder Committee, 1970; Takahashi et al., 1995b; Miyama et al., 1997; Götz and Huttner, 2005; Bystron et al., 2008; Kowalczyk et al., 2009). Whereas neuronal production from the SPP of the outer SVZ plays an important role in gyrus formation, particularly in primates (Lui et al., 2011; Florio and Huttner, 2014; Dehay et al., 2015), its role in lissencephalic animals is a subject of further investigation (Takahashi et al., 1995b; Mitsuhashi and Takahashi, 2016). In this context, we have shown that VPA exposure in utero 
did not alter the population size of SPP (determined here as the S-phase marker-positive cells in the SVZ/VZ interface or as the Tbr2-positive BPs) on E16 (Fig. 6F) or on E18 (determined as the S-phase marker-positive cells in the SVZ). Thus, we have concluded that Q alteration of the VZ NPCs is the predominant mechanism of the increase of projection neurons.

The neocortices contain not only projection neurons but interneurons produced in the ganglionic eminences as well. There was no alteration in the number of interneurons by VPA exposure in utero in the present study (Fig. $3 C$ ), although our method may not be sensitive enough to detect subtle changes in this relatively small population. However, since the great majority of neocortical neurons $(\leq 80 \%)$ are projection neurons (Coyle and Enna, 1976), we concluded that the neocortical dysgenesis induced by VPA exposure in utero arises mainly, if not exclusively, from the increase of projection neurons produced from the VZ NPCs.

\section{Increased expression of cell cycle regulatory proteins in NPCs by VPA exposure in utero}

The G1-phase regulatory proteins control the cell proliferation/differentiation characteristics of the NPCs as evidenced by previous findings that (1) the cdk4/cyclinD1 complex prevents G1 lengthening and NPC differentiation (Lange et al., 2009), and (2) cdk inhibitor $\mathrm{p} 27^{\mathrm{Kip} 1}$ inhibits cell cycle progression and induces NPC differentiation (Mitsuhashi et al., 2001; Tarui et al., 2005). A quantitative and/or qualitative balance between G1-phase regulatory proteins with opposing functions may regulate the progression of the cell cycle and the induction of differentiation. Our results showed that VPA exposure in utero induced the expression of both differentiation-inhibitory proteins (cyclinD1, cdk2, and cdk4) and a differentiation-inducing protein (p27 Kip1; Fig. $9 A, B)$. This nonspecific increase in G1-phase regulatory proteins may explain the discrepancy between our results on the SPP and those of a previous study reporting increased generation of the BPs by specific induction of cdk4/cyclinD1 (Lange et al., 2009). We speculate that the differentiation-inhibitory proteins were predominant in amount or effect compared with the differentiation-inducing proteins, during the early to middle phases of neuronogenesis when VPA exposure in utero markedly inhibited NPC differentiation (Fig. 6B, C). Additionally, previous studies have reported that (1) nonsense mutation in HDAC1 encoding genes and exposure to trichostatin A, another HDAC inhibitor, both inhibited NPC differentiation in the developing zebrafish retina (Yamaguchi et al., 2005) and (2) inactivation of histone acetyltransferase by Trrap deletion downregulates the expression of cell cycle regulatory genes and promotes NPC differentiation in mice (Tapias et al., 2014). Both results indicate regulation of the proliferation/differentiation characteristics of the NPCs by acetylation of histone proteins. Although the underlying mechanisms are still unclear, we suggest that the HDAC inhibitory activity of VPA may be involved in the inhibition of NPC differentiation.

\section{Growth retardation during the earliest stages of embryogenesis by VPA exposure in utero}

A decrease in the number of NPCs "before" the onset of neuronogenesis in the VPA-exposed embryos was indicated by the reduced rostrocaudal length of the forebrains on E11 (Fig. 4A). Furthermore, growth retardation was not restricted to the central nervous system in the VPA-exposed embryos, as we also observed decreased crown-rump length on E11 (Fig. 4A). In previous reports, VPA exposure increased caspase- 3 expression in murine embryonic head tissues on E9 (Tung and Winn, 2011) and p21 ${ }^{\mathrm{Cip} 1 / \mathrm{WAF} 1}$ expression in a human cancer cell line (Zupkovitz et al., 2010), which might have occurred in the VPA-exposed em- bryos before the onset of neuronogenesis in the present study. However, VPA exposure after E12, even when these early effects of VPA were excluded, reportedly increased the neocortical thickness and neuronal number (Sabers et al., 2014).

Furthermore, as estimated from the regression curves of the Q fraction in the VPA-exposed embryos (Fig. 6C), Q alteration was capable of increasing both the maximum number of NPCs (at $Q=0.5$ ) and neuronal production during the latter phase of neuronogenesis in the VZ, even if the number of NPCs at the onset of neuronogenesis was lower than that in controls (Fig. $10 A, B)$. Thus, the altered pattern of the $\mathrm{Q}$ fraction ascent during neuronogenesis affected the neuron production sufficiently to compensate for the reduction in the NPC population size at the outset of neocortical histogenesis.

\section{Possible mechanism for impairment of higher brain functions by VPA exposure in utero}

As previously mentioned, VPA exposure in utero increases the risk of impairments in higher brain functions, including autism spectrum disorders in humans (Bromley et al., 2013; Christensen et al., 2013). Autistic features are also reported in rodents exposed to high doses of VPA over a short term during the early phase of neuronogenesis (Schneider and Przewłocki, 2005). A relative increase in excitatory to inhibitory synaptic function is suggested as a pathogenetic mechanism of autism both in humans and in mice exposed to VPA in utero (Rubenstein and Merzenich, 2003; Gogolla et al., 2009). Indeed, a previous study has reported an increased neuronal number in the postmortem brains of children with autism (Courchesne et al., 2011).

Interestingly, VPA exposure in utero increased the number of projection neurons without altering the number of interneurons in the present study, though this result could be a matter of methodological sensitivity (Fig. 3B,C). In other words, VPA exposure in utero may impair the excitatory/inhibitory ratio of neuronal function by specifically increasing the number of excitatory projection neurons (and excitatory synapses). Analyzing the higher brain functions of mice exposed to low doses of VPA throughout their embryonic period will be an important topic of future investigation.

This report showed that in utero exposure to an HDAC inhibitory agent, VPA, increased the number of excitatory projection neurons in the postnatal neocortices by inhibiting NPC differentiation in embryos. Such abnormalities may not only cause neocortical dysgenesis but also impairments in higher brain functions. We expect that further studies on the epigenetic modification mechanisms of NPC proliferation/differentiation will yield insights into the pathogenesis of "environment-induced" neuronal dysgenesis, possibly leading to novel treatments.

\section{References}

Boulder Committee (1970) Embryonic vertebrate central nervous system: revised terminology. The Boulder Committee. Anat Rec 166:257-261. CrossRef Medline

Bromley RL, Mawer GE, Briggs M, Cheyne C, Clayton-Smith J, García-Fiñana M, Kneen R, Lucas SB, Shallcross R, Baker GA (2013) The prevalence of neurodevelopmental disorders in children prenatally exposed to antiepileptic drugs. J Neurol Neurosurg Psychiatry 84:637-643. CrossRef Medline

Bystron I, Blakemore C, Rakic P (2008) Development of the human cerebral cortex: Boulder Committee revisited. Nat Rev Neurosci 9:110-122. CrossRef Medline

Caviness VS Jr (1975) Architectonic map of neocortex of the normal mouse. J Comp Neurol 164:247-263. CrossRef Medline

Christensen J, Grønborg TK, Sørensen MJ, Schendel D, Parner ET, Pedersen LH, Vestergaard M (2013) Prenatal valproate exposure and risk of autism spectrum disorders and childhood autism. JAMA 309:1696-1703. CrossRef Medline 
Courchesne E, Mouton PR, Calhoun ME, Semendeferi K, Ahrens-Barbeau C, Hallet MJ, Barnes CC, Pierce K (2011) Neuron number and size in prefrontal cortex of children with autism. JAMA 306:2001-2010. CrossRef Medline

Coyle JT, Enna SJ (1976) Neurochemical aspects of the ontogenesis of GABAnergic neurons in the rat brain. Brain Res 111:119-133. CrossRef Medline

Dehay C, Kennedy H, Kosik KS (2015) The outer subventricular zone and primate-specific cortical complexification. Neuron 85:683-694. CrossRef Medline

Englund C, Fink A, Lau C, Pham D, Daza RA, Bulfone A, Kowalczyk T, Hevner RF (2005) Pax6, Tbr2, and Tbr1 are expressed sequentially by radial glia, intermediate progenitor cells, and postmitotic neurons in developing neocortex. J Neurosci 25:247-251. CrossRef Medline

Florio M, Huttner WB (2014) Neural progenitors, neurogenesis and the evolution of the neocortex. Development 141:2182-2194. CrossRef Medline

Gogolla N, Leblanc JJ, Quast KB, Südhof TC, Fagiolini M, Hensch TK (2009) Common circuit defect of excitatory-inhibitory balance in mouse models of autism. J Neurodev Disord 1:172-181. CrossRef Medline

Goto T, Mitsuhashi T, Takahashi T (2004) Altered patterns of neuron production in the p27 knockout mouse. Dev Neurosci 26:208-217. Medline

Göttlicher M, Minucci S, Zhu P, Krämer OH, Schimpf A, Giavara S, Sleeman JP, Lo Coco F, Nervi C, Pelicci PG, Heinzel T (2001) Valproic acid defines a novel class of HDAC inhibitors inducing differentiation of transformed cells. EMBO J 20:6969-6978. CrossRef Medline

Götz M, Huttner WB (2005) The cell biology of neurogenesis. Nat Rev Mol Cell Biol 6:777-788. CrossRef Medline

Jentink J, Loane MA, Dolk H, Barisic I, Garne E, Morris JK, de Jong-van den Berg LT, de Jong-van den Berg LT (2010) Valproic acid monotherapy in pregnancy and major congenital malformations. N Engl J Med 362:21852193. CrossRef Medline

Jones EG, Rakic P (2010) Radial columns in cortical architecture: it is the composition that counts. Cereb Cortex 20:2261-2264. CrossRef Medline

Juliandi B, Abematsu M, Sanosaka T, Tsujimura K, Smith A, Nakashima K (2012) Induction of superficial cortical layer neurons from mouse embryonic stem cells by valproic acid. Neurosci Res 72:23-31. CrossRef Medline

Kowalczyk T, Pontious A, Englund C, Daza RA, Bedogni F, Hodge R, Attardo A, Bell C, Huttner WB, Hevner RF (2009) Intermediate neuronal progenitors (basal progenitors) produce pyramidal-projection neurons for all layers of cerebral cortex. Cereb Cortex 19:2439-2450. CrossRef Medline

Lange C, Huttner WB, Calegari F (2009) Cdk4/cyclinD1 overexpression in neural stem cells shortens G1, delays neurogenesis, and promotes the generation and expansion of basal progenitors. Cell Stem Cell 5:320-331. CrossRef Medline

Löscher W (1999) Valproate: a reappraisal of its pharmacodynamic properties and mechanisms of action. Prog Neurobiol 58:31-59. CrossRef Medline

Lui JH, Hansen DV, Kriegstein AR (2011) Development and evolution of the human neocortex. Cell 146:18-36. CrossRef Medline

Meador KJ, Baker GA, Browning N, Cohen MJ, Bromley RL, Clayton-Smith J, Kalayjian LA, Kanner A, Liporace JD, Pennell PB, Privitera M, Loring DW, Loring DW (2013) Fetal antiepileptic drug exposure and cognitive outcomes at age 6 years (NEAD study): a prospective observational study. Lancet Neurol 12:244-252. CrossRef Medline

Mitsuhashi T, Takahashi T (2016) Proliferation and differentiation characteristics of neural stem cells during course of cerebral cortical histogenesis. Congenit Anom (Kyoto) 56:6-11. CrossRef Medline

Mitsuhashi T, Aoki Y, Eksioglu YZ, Takahashi T, Bhide PG, Reeves SA, Caviness VS Jr (2001) Overexpression of p27Kip1 lengthens the G1 phase in a mouse model that targets inducible gene expression to central nervous system progenitor cells. Proc Natl Acad Sci U S A 98:6435-6440. CrossRef Medline

Mitsuhashi T, Yonemoto J, Sone H, Kosuge Y, Kosaki K, Takahashi T (2010) In utero exposure to dioxin causes neocortical dysgenesis through the actions of p27Kip1. Proc Natl Acad Sci U S A 107:16331-16335. CrossRef Medline

Miyama S, Takahashi T, Nowakowski RS, Caviness VS Jr (1997) A gradient in the duration of the G1 phase in the murine neocortical proliferative epithelium. Cereb Cortex 7:678-689. CrossRef Medline

Nau H (1985) Teratogenic valproic acid concentrations: infusion by implanted minipumps vs conventional injection regimen in the mouse. Toxicol Appl Pharmacol 80:243-250. CrossRef Medline

Phiel CJ, Zhang F, Huang EY, Guenther MG, Lazar MA, Klein PS (2001) Histone deacetylase is a direct target of valproic acid, a potent anticonvul- sant, mood stabilizer, and teratogen. J Biol Chem 276:36734-36741. CrossRef Medline

Rakic P (1988) Specification of cerebral cortical areas. Science 241:170-176. CrossRef Medline

Rubenstein JL, Merzenich MM (2003) Model of autism: increased ratio of excitation/inhibition in key neural systems. Genes Brain Behav 2:255267. CrossRef Medline

Sabers A, Bertelsen FC, Scheel-Krüger J, Nyengaard JR, Møller A (2014) Long-term valproic acid exposure increases the number of neocortical neurons in the developing rat brain. A possible new animal model of autism. Neurosci Lett 580:12-16. CrossRef Medline

Schneider T, Przewłocki R (2005) Behavioral alterations in rats prenatally exposed to valproic acid: animal model of autism. Neuropsychopharmacology 30:80-89. CrossRef Medline

Strahl BD, Allis CD (2000) The language of covalent histone modifications. Nature 403:41-45. CrossRef Medline

Takahashi T, Nowakowski RS, Caviness VS Jr (1992) BUdR as an S-phase marker for quantitative studies of cytokinetic behaviour in the murine cerebral ventricular zone. J Neurocytol 21:185-197. CrossRef Medline

Takahashi T, Nowakowski RS, Caviness VS Jr (1995a) The cell cycle of the pseudostratified ventricular epithelium of the embryonic murine cerebral wall. J Neurosci 15:6046-6057. Medline

Takahashi T, Nowakowski RS, Caviness VS Jr (1995b) Early ontogeny of the secondary proliferative population of the embryonic murine cerebral wall. J Neurosci 15:6058-6068. Medline

Takahashi T, Nowakowski RS, Caviness VS Jr (1996a) Interkinetic and migratory behavior of a cohort of neocortical neurons arising in the early embryonic murine cerebral wall. J Neurosci 16:5762-5776. Medline

Takahashi T, Nowakowski RS, Caviness VS Jr (1996b) The leaving or Q fraction of the murine cerebral proliferative epithelium: a general model of neocortical neuronogenesis. J Neurosci 16:6183-6196. Medline

Takahashi T, Goto T, Miyama S, Nowakowski RS, Caviness VS Jr (1999) Sequence of neuron origin and neocortical laminar fate: relation to cell cycle of origin in the developing murine cerebral wall. J Neurosci 19: 10357-10371. Medline

Tapias A, Zhou ZW, Shi Y, Chong Z, Wang P, Groth M, Platzer M, Huttner W, Herceg Z, Yang YG, Wang ZQ (2014) Trrap-dependent histone acetylation specifically regulates cell-cycle gene transcription to control neural progenitor fate decisions. Cell Stem Cell 14:632-643. CrossRef Medline

Tarui T, Takahashi T, Nowakowski RS, Hayes NL, Bhide PG, Caviness VS (2005) Overexpression of $27 \mathrm{Kip}$ 1, probability of cell cycle exit, and laminar destination of neocortical neurons. Cereb Cortex 15:1343-1355. Medline

Tomson T, Marson A, Boon P, Canevini MP, Covanis A, Gaily E, Kälviäinen R, Trinka E (2015) Valproate in the treatment of epilepsy in girls and women of childbearing potential. Epilepsia 56:1006-1019. CrossRef Medline

Tou L, Liu Q, Shivdasani RA (2004) Regulation of mammalian epithelial differentiation and intestine development by class I histone deacetylases. Mol Cell Biol 24:3132-3139. CrossRef Medline

Tung EW, Winn LM (2011) Valproic acid-induced DNA damage increases embryonic p27(KIP1) and caspase-3 expression: a mechanism for valproic-acid induced neural tube defects. Reprod Toxicol 32:255-260. CrossRef Medline

Verney C, Takahashi T, Bhide PG, Nowakowski RS, Caviness VS Jr (2000) Independent controls for neocortical neuron production and histogenetic cell death. Dev Neurosci 22:125-138. CrossRef Medline

Wade PA (2001) Transcriptional control at regulatory checkpoints by histone deacetylases: molecular connections between cancer and chromatin. Hum Mol Genet 10:693-698. CrossRef Medline

Wood AG, Chen J, Barton S, Nadebaum C, Anderson VA, Catroppa C, Reutens DC, O'Brien TJ, Vajda F (2014) Altered cortical thickness following prenatal sodium valproate exposure. Ann Clin Transl Neurol 1:497-501. CrossRef Medline

Yamaguchi M, Tonou-Fujimori N, Komori A, Maeda R, Nojima Y, Li H, Okamoto H, Masai I (2005) Histone deacetylase 1 regulates retinal neurogenesis in zebrafish by suppressing Wnt and Notch signaling pathways. Development 132:3027-3043. CrossRef Medline

Zupkovitz G, Grausenburger R, Brunmeir R, Senese S, Tischler J, Jurkin J, Rembold M, Meunier D, Egger G, Lagger S, Chiocca S, Propst F, Weitzer G, Seiser C (2010) The cyclin-dependent kinase inhibitor p21 is a crucial target for histone deacetylase 1 as a regulator of cellular proliferation. Mol Cell Biol 30:1171-1181. CrossRef Medline 